Federal Reserve Bank of Minneapolis

Research Department Staff Report 511

May 2015

\title{
Coordination and Crisis in Monetary Unions
}

\author{
Mark Aguiar \\ Princeton University \\ Manuel Amador \\ Federal Reserve Bank of Minneapolis \\ Emmanuel Farhi \\ Harvard University \\ Gita Gopinath \\ Harvard University
}

\begin{abstract}
We study fiscal and monetary policy in a monetary union with the potential for rollover crises in sovereign debt markets. Member-country fiscal authorities lack commitment to repay their debt and choose fiscal policy independently. A common monetary authority chooses inflation for the union, also without commitment. We first describe the existence of a fiscal externality that arises in the presence of limited commitment and leads countries to over-borrow; this externality rationalizes the imposition of debt ceilings in a monetary union. We then investigate the impact of the composition of debt in a monetary union, that is the fraction of high-debt versus low-debt members, on the occurrence of self-fulfilling debt crises. We demonstrate that a high-debt country may be less vulnerable to crises and have higher welfare when it belongs to a union with an intermediate mix of high- and low-debt members, than one where all other members are low-debt. This contrasts with the conventional wisdom that all countries should prefer a union with low-debt members, as such a union can credibly deliver low inflation. These findings shed new light on the criteria for an optimal currency area in the presence of rollover crises.
\end{abstract}

Keywords: Debt crisis; Coordination failures; Monetary union; Fiscal policy JEL classification: E4, E5, F3, F4

\footnotetext{
*Corresponding author: Gita Gopinath, Littauer Center 206, 1805 Cambridge Street, Cambridge, MA 02138, USA. Email: gopinath@harvard.edu. Tel: 617-495-8161. Fax: 617-495-8570. We thank Cristina Arellano, Patrick Kehoe, Enrique Mendoza, Tommaso Monacelli, Helene Rey, and seminar participants at several places for useful comments. We also thank Ben Hebert for excellent research assistance. Manuel Amador acknowledges support from the NSF (award number 0952816). The views expressed herein are those of the authors and not necessarily those of the Federal Reserve Bank of Minneapolis or the Federal Reserve System.
} 


\section{Introduction}

Monetary unions are characterized by centralized monetary policy and decentralized fiscal policy. The problems associated with stabilizing the impact on welfare of asymmetric shocks across countries with a common monetary policy have been studied in depth starting with the seminal work of Mundell (1961) on optimal currency areas. The ongoing Euro crisis has, however, brought to the forefront a novel set of issues regarding welfare of countries in a monetary union with asymmetric debt levels that are subject to rollover risk in sovereign debt markets. To study these issues we provide a framework that describes the impact of centralized monetary policy and decentralized fiscal policy on debt dynamics and exposure to self-fulfilling debt crises. This analysis sheds new light on the criteria for an optimal currency area in the presence of rollover crises. ${ }^{1}$

The environment consists of individual fiscal authorities that choose how much to consume and borrow by issuing nominal bonds. A common monetary authority chooses inflation for the union, taking as given the fiscal policy of its member countries. Both fiscal and monetary policy is implemented without commitment. The lack of commitment on fiscal policy raises the possibility of default. The lack of commitment on monetary policy makes the central bank vulnerable to the temptation to inflate away the real value of its members' nominal debt. In choosing the optimal policy ex post, the monetary authority trades off the distortionary costs of inflation against the fiscal benefits of debt reduction. Lenders recognize this temptation and charge a higher nominal interest rate ex ante, making ex post inflation self-defeating. ${ }^{2}$

The joint lack of commitment and coordination gives rise to a fiscal externality in a monetary union. The monetary authority's incentive to inflate depends on the aggregate value of debt in the union. Each country in the union ignores the impact of its borrowing decisions on the evolution of aggregate debt and hence on inflation. We compare this to the case of a small open economy where the fiscal and monetary authority coordinate on decisions while maintaining the assumption of limited commitment. We show that a monetary union leads to higher debt, higher long-run inflation and lower welfare. While coordination eliminates the fiscal externality, it does not replicate the full-commitment outcome. Full commitment in monetary policy gives rise to the first best level of welfare, with or without coordination on fiscal policy. These two cases allow us to decompose the welfare losses in the monetary union due to lack of coordination versus lack of commitment. The presence of this fiscal

\footnotetext{
${ }^{1}$ For a survey on optimal currency areas see Silva and Tenreyro (2010).

${ }^{2}$ Barro and Gordon (1983) in a seminal paper demonstrate the time inconsistency of monetary policy and the resulting inflationary bias.
} 
externality rationalizes the imposition of debt ceilings in a monetary union. ${ }^{3}$

In this context of debt overhang onto monetary policy, we explore the composition of the monetary union. In particular, we consider a union comprised of high- and low-debt economies, where the groups differ by the level of debt at the start of the monetary union. Consider first the case without rollover crises, that is there is no coordination failure among lenders in rolling over maturing debt. While inflation is designed to alleviate the real debt burden of the members, all members, regardless of debt level, would like to be part of a lowdebt monetary union. This is because in a high-debt monetary union the common monetary authority is tempted to inflate to provide debt relief ex post but the lenders anticipate this and the higher inflation is priced into interest rates ex ante. Consequently, the members in a union obtain no debt relief and only incur the deadweight cost of inflation. A lowdebt monetary union therefore better approximates the full-commitment allocation of low inflation and correspondingly low nominal interest rates. High-debt members recognize they will roll over their nominal bonds at a lower interest rate in such a union, thereby benefiting from joining a low-debt monetary union. This agreement on membership criteria, however, does not survive the possibility of rollover crises.

In particular, we consider equilibria in which lenders fail to coordinate on rolling over maturing debt. This opens the door to self-fulfilling debt crises for members with high enough debt levels. In this environment, there is a trade-off regarding membership criteria. As in the no-crisis benchmark, a low-debt union can credibly promise low inflation, which leads to low nominal interest rates and low distortions. However, in the presence of rollover crises monetary policy not only should deliver low inflation in tranquil times but also serve as a lender of last resort to address (and potentially eliminate) coordination failures among lenders. The monetary authority of a union comprised mainly of low-debtors may be unwilling to inflate in the event of a crisis, as such inflation benefits only the highly indebted members at the expense of higher inflation in all members. That is, while low-debt membership provides commitment to deliver low inflation in good times, it undermines the central bank's credibility to act as lender of last resort. Therefore, highly indebted economies prefer a monetary union in which a sizeable fraction of members also have high debt, balancing commitment to low inflation against commitment to act as a lender of last resort.

Importantly, the credibility to inflate in response to a crisis (an off-equilibrium promise) may eliminate a self-fulfilling crisis without the need to inflate in equilibrium. This implication of the model is consistent with the events in the summer of 2012 when the announcement

\footnotetext{
${ }^{3}$ Debt ceilings on member countries are a feature of the Stability and Growth Pact in the eurozone. Similar debt ceilings exist on individual states in the U.S. Von Hagen and Eichengreen (1996) provide evidence of debt constraints on sub-national governments in a large number of countries, each of which works like a monetary union.
} 
by Mario Draghi that the European Central Bank (ECB) would do "whatever it takes" to defend the euro sharply reduced the borrowing costs for Spain, Italy, Portugal, Greece and Ireland. ${ }^{4}$ This put the brakes on what arguably looked like a self-fulfilling debt crisis in the eurozone, without the ECB having to buy any distressed country debt. ${ }^{5}$

One way to interpret these findings is to consider the decision of an indebted country to join a monetary union or to have independent control over its monetary policy. In the absence of rollover crises the country is best served by joining a monetary union with low aggregate debt, as in such a union the monetary authority will deliver low inflation. This is the classic argument for joining a union with a monetary authority that has greater credibility to keep inflation low. ${ }^{6}$ By contrast, in the presence of self-fulfilling rollover crises, the country can be better off by joining a monetary union with intermediate level of aggregate debt, as this reduces its vulnerability to self-fulfilling crises compared to a union with low aggregate debt. Our analysis therefore provides a new consideration in the design of optimal currency areas; namely, eliminating self-fulfilling debt crises. $^{7}$

Importantly, inflation credibility can be influenced endogenously through the debt composition of the monetary union. These findings shed new light on the criteria for an optimal currency area and relates to the literature on institutional design for monetary policy. Rogoff (1985b) highlighted the virtues of delegating monetary authority to a central banker whose objective function can differ from society's, so as to gain inflation credibility. Implementing such delegation however may be difficult if society disagrees with the central banker's objectives. Here we demonstrate how debt characteristics of monetary union members endogenously impact the inflation credibility of the monetary authority.

The rest of the paper is structured as follows. Section 2 places our paper in the context of the existing literatures. Section 3 presents the model in an environment without rollover crises. It characterizes the fiscal externality in a monetary union. Section 4 analyzes the case with rollover crises. Section 5 discusses the implications for the optimal composition

\footnotetext{
${ }^{4}$ De Grauwe (2011) emphasizes the importance of the lender of last resort role for the ECB.

${ }^{5}$ The ECB announcement in 2012 was accompanied by the setting up of an Outright Monetary Transactions facility to purchase distressed country debt. This intervention brought down spreads on distressed country debt without the ECB actually buying any such debt (which is an important difference from the subsequent 2015 monetary accommodation in the form of a Quantitative Easing program involving euro area sovereign bonds). An alternative strategy would be for the core countries to promise fiscal transfers to the periphery in the event of the crisis. The political economy constraints on engineering such transfers and the weak credibility of such promises make the ECB intervention more practical and credible, which is why we focus on the latter.

${ }^{6}$ Alesina and Barro (2002) highlight the benefits of joining a currency union whose monetary authority has greater commitment to keeping inflation low in an environment where Keynesian price stickiness provides an incentive for monetary authorities to inflate ex post.

${ }^{7}$ To the extent that non-debtors suffer when co-unionists default, the non-debt members will also have a non-monotonic relationship between their welfare and the heterogeneity of the union.
} 
of a union an indebted country is considering joining, and Section 6 concludes. Proofs and some technical details are relegated to the appendix.

\section{Literature Review}

In this section we describe our contribution to the existing literature on optimal currency areas. Our focus, unlike most of the existing literature, is on the interaction between inflation, nominal debt dynamics and exposure to self-fulfilling debt crises in monetary unions.

A main finding of our analysis, as previously described, is that when subject to rollover risk an indebted country can be better off joining a monetary union with intermediate level of aggregate debt as compared to one with low aggregate debt. The optimal currency area literature has emphasized the benefits to a country of joining a union that is "similar" to itself in the context of Keynesian macro stabilization. Our criterion for optimal currency areas also highlights that a country with high debt can be better off by joining a union that has similar high-debtors as it then receives the benefit of monetary policy intervention in the event of a rollover crisis.

However, there are two important reasons our criterion differs from the existing literature. First, there is a limit to the benefits of similarity in our environment. A high-debt country can be worse off by joining a union where everyone else is like itself as compared to one where only an intermediate number of countries are like itself. This is because in the former case the common monetary authority is tempted to inflate at all times, generating high inflation in normal times that in turn makes it hard to generate surprise inflation in crisis times. Such a monetary authority is unable to generate state-contingent inflation and is therefore not successful in using inflation to prevent a rollover crisis. A high-debt country in this case experiences the cost of high inflation without escaping a rollover crisis. This lowers its welfare compared to joining a union with an intermediate level of high-debtors. This contrasts with the Keynesian macro stabilization argument for symmetry in the literature where welfare always increases with greater similarity.

Second, despite heterogeneity across countries in debt levels, active monetary intervention to help high debtors does not necessarily make low debt countries worse off. This is because the threat to inflate in response to a crisis is an off-equilibrium threat that prevents a rollover crisis from occurring and therefore the higher inflation is not actually experienced. This intervention is similar to the "Draghi put" whereby a crisis was averted by announcing the ECB's intention to buy sovereign bonds in the event of a crisis without having to buy any sovereign debt in equilibrium. This again differs from the standard symmetry argument in the literature where monetary policy interventions are equilibrium phenomena and therefore 
trade-offs necessarily exist.

The other contribution relates to the fiscal externality in a monetary union. The combination of time inconsistency in monetary policy and of decentralized fiscal policy gives rise to a fiscal externality in a monetary union. Fiscal externalities have indeed been previously described in the literature, specifically in the important contributions of Chari and Kehoe (2007) and Chari and Kehoe (2008) who describe the role of commitment in eliminating the fiscal externality. ${ }^{8}$ We differ from these papers in that we demonstrate the separate role of lack of coordination among fiscal authorities and monetary authority, and of lack of commitment, in affecting inflation, debt dynamics and welfare in a monetary union. The lack of coordination is a defining feature of monetary unions and so to isolate the role it plays in impacting welfare we contrast the solution to the case where decision making is coordinated but commitment is still lacking. Then we add in the role of lack of commitment. We therefore decompose the welfare losses relative to the first best that arise from lack of coordination and that which arises from lack of commitment.

In other literature Beetsma and Uhlig (1999) provide an argument for debt ceilings in a monetary union that arise from political economy constraints, namely short-sighted governments. Dixit and Lambertini (2001) and Dixit and Lambertini (2003) examine the implications for output and inflation in a monetary union where fiscal policy is decentralized and monetary policy is centralized, allowing for the authorities to have conflicting goals for output and inflation. Cooper et al. (2014) and Cooper et al. (2010) examine the interaction between fiscal and monetary policy in a monetary union including exploring the incentives for a monetary bailout in the presence of regional debt. Araujo et al. (2012) consider some implications of currency denomination of debt in the presence of self-fulfilling crises.

There exists an important literature jointly analyzing fiscal and monetary policies in a monetary union in the presence of New Keynesian frictions such as for example Beetsma and Jensen (2005), Gali and Monacelli (2008), Ferrero (2009) and Farhi and Werning (2013). Separately Rogoff (1985a) analyzes coordination and commitment of monetary policies in the context of a model with nominal rigidities. The focus of our paper differs from this literature as it is on debt, inflation and crises.

\footnotetext{
${ }^{8}$ Velasco (2000) describes an interesting fiscal externality that arises in a "tragedy of commons" environment where multiple groups/state governments share a common fiscal resource.
} 


\section{Model}

\subsection{Environment}

There is a measure-one continuum of small open economies, indexed by $i \in[0,1]$, that form a monetary union. Fiscal policy is determined independently at the country-level, while monetary policy is chosen by a single monetary authority. In this section we consider the case where economies are not subject to rollover risk, that is lenders can commit to roll over debt. We introduce rollover risk in section 4.

Time is continuous and there is a single traded consumption good with a world price normalized to one. Each economy is endowed with $y_{i}=y$ units of the good each period that is assumed to be constant. The domestic currency price at time $t$ is denoted $P_{t}=P(t)=$ $P(0) e^{\int_{0}^{t} \pi(t) d t}$, where $\pi(t)$ denotes the rate of inflation at time $t .{ }^{9}$ The domestic-currency price level is the same across member countries and its evolution is controlled by the central monetary authority. ${ }^{10}$

Preferences Each fiscal authority has preferences over paths for consumption and inflation given by:

$$
U^{f}=\int_{0}^{\infty} e^{-\rho t}\left(u\left(c_{i}(t)\right)-\psi(\pi(t))\right) d t
$$

Utility over consumption satisfies the usual conditions, $u^{\prime}>0, u^{\prime \prime}<0, \lim _{c \downarrow 0} u^{\prime}(c)=\infty$. As the fiscal authority controls $c_{i}(t), u(c)$ is the relevant portion of the objective function in terms of fiscal choices. The second term, $\psi(\pi(t))$ reflects the preferences of the fiscal authority in each country over the inflation choices made by the central monetary authority. This term captures in reduced form the distortionary costs of inflation borne by the individual countries. For tractability purposes we assume $\psi(\pi(t)) \equiv \psi_{0} \pi(t)$ and we restrict the choice of inflation to the interval $\pi \in[0, \bar{\pi}]$.

The monetary authority preferences are an equally-weighted aggregate over all the economies

\footnotetext{
${ }^{9}$ As we shall see, we assume that the monetary authority's policy selects $\pi(t) \leq \bar{\pi}<\infty$, and so the domestic price level is a continuous function of time. Moreover, we treat the initial price level $P(0)$ as a primitive of the environment, which avoids complications arising from a large devaluation in the initial period. This is similar to bounding the initial capital levy in a canonical Ramsey taxation program. This also speaks to the differences between our environment and the "fiscal theory of the price level." In that literature, the initial price level adjusts to ensure that real liabilities equal a given discounted stream of fiscal surpluses. In our environment, we take the initial price level as given and solve for the equilibrium path of fiscal surpluses and inflation.

${ }^{10}$ For evidence of convergence in euro area inflation rates and price levels see Lopez and Papell (2012) and Rogers (2001).
} 
in the monetary union:

$$
U^{m}=\int_{0}^{\infty} e^{-\rho t}\left(\int_{i} u\left(c_{i}(t)\right) d i-\psi(\pi(t))\right) d t .
$$

Bond Markets Each country $i$ can issue a non-contingent nominal bond that must be continuously rolled over. Denote $B_{i}(t)$ the outstanding stock of country $i$ 's debt, the real value of which is denoted $b_{i}(t) \equiv \frac{B_{i}(t)}{P(t)}$. We normalize the price of a bond to one in local currency and clear the market by allowing the equilibrium nominal interest rate $r_{i}(t)$ to adjust. Denoting country $i$ 's consumption by $c_{i}(t)$, the evolution of nominal debt is given by:

$$
\dot{B}_{i}(t)=P(t)\left(c_{i}(t)-y\right)+r_{i}(t) B_{i}(t)
$$

which can be re-written in terms of real debt using the identity $\dot{b}(t) / b(t)=\dot{B}(t) / B(t)-\pi(t)$ as

$$
\dot{b}_{i}(t)=c_{i}(t)-y+\left(r_{i}(t)-\pi(t)\right) b_{i}(t)
$$

The rate of change of the real debt is equal to the sum of the real trade deficit and the real interest payment on the debt. The role of inflation in reducing the real payments on the debt for a given nominal interest rate is evident from the constraint.

Bonds are purchased by risk-neutral lenders who behave competitively and have an opportunity cost of funds $\rho$, same as the countries' discount rate. We ignore the resource constraint of lenders as a group by assuming that the monetary union is small in world financial markets (although each country is a large player in terms of its own debt). In particular, we assume that country $i$ 's bond market clears as long as the expected real return is $\rho$.

As we discuss in the next subsection, fiscal authorities cannot commit to repay loans. In particular, at any moment $T$, a fiscal authority can default and pay zero. We assume that if it defaults, it is punished by permanent loss of access to international debt markets plus a loss of output given by the parameter $\chi$. We also assume that when an individual country makes the decision to default it is not excluded from the union. We let $\underline{V}(T)$ represent the continuation value after a default.

$$
\underline{V}(T)=\frac{u((1-\chi) y)}{\rho}-\int_{T}^{\infty} e^{-\rho(t-T)} \psi(\pi(t)) d t .
$$


Note that the default payoff depends on union-wide inflation, but does not depend on the amount of debt prior to default. ${ }^{11}$

In the above formulation, we distinguish outright default from implicit partial default through inflation for a number of reasons. First, outright default in the present model is a choice of the fiscal authorities, while inflation is chosen by the monetary authority. Second, the model allows us to consider environments where the two costs of default are treated differentily by market participants. For example, the period of high inflation during the 1970s in the U.S. and Western Europe lead to a reduction in the real value of outstanding bonds; but the governments did not enter a renegotiation with creditors or lose access to financial markets, as is typically the case during an outright default episode.

\subsection{Symmetric Markov Perfect Equilibrium}

We are interested in the equilibrium of the game between competitive lenders, individual fiscal authorities, and a centralized monetary authority. In particular, we construct a Markov perfect equilibrium in which each member country behaves symmetrically in terms of policy functions. The payoff-relevant state variables are the outstanding amounts of nominal debt issued by member countries and the aggregate price level. We can substitute the real value of debt using the assumption that $P(0)$ is given.

In general, the aggregate state is the distribution of bonds across all members of the monetary union. We are interested in environments in which members differ in their debt stocks, allowing us to explore potential disagreement among members regarding policy and the optimal composition of the monetary union. On the other hand, tractability requires limiting the dimension of the state variable. To this end, we consider a union comprised of high and low debt countries in the initial period. Let $\eta \in(0,1]$ denote the measure of high-debt economies, and denote this group $H$ and the low-debt group $L$. For tractability, we assume that there is no within-group heterogeneity; that is, $b_{i}(0)=b_{H}(0)$ for all $i \in H$ and $b_{j}(0)=b_{L}(0)$ for all $j \in L$, with $b_{H}(0)>b_{L}(0)$.

We focus on equilibria with symmetric policy functions, and so the initial within-group symmetry is preserved in equilibrium. It is useful to introduce the following notation. Let $\boldsymbol{b}(t)_{H}=\frac{1}{\eta} \int_{i \in H} b_{i}(t) d i$ denote the mean debt stock of the high-debt group, and let similarly $\boldsymbol{b}(t)_{L}=\frac{1}{1-\eta} \int_{i \in L} b_{i}(t) d i$ denote the debt stock of the low-debt group. Let $\boldsymbol{b}=\left(\boldsymbol{b}_{H}, \boldsymbol{b}_{L}\right)$ denote the vector of mean debt stocks in the two subgroups of members.

\footnotetext{
${ }^{11}$ There is limited well identified empirical evidence on the costs of sovereign default. Therefore we stay close to the standard assumptions in the sovereign debt literature on the costs of default, including that costs are independent of the level of debt prior to default. See Aguiar and Amador (2014) for a recent survey of the sovereign debt literature.
} 
Using this notation, the relevant state variable for an individual fiscal authority is the triplet $\left(b, \boldsymbol{b}_{H}, \boldsymbol{b}_{L}\right)=(b, \boldsymbol{b})$, where the first argument is the country's own debt level and the latter characterizes the aggregate state. Let $C(b, \boldsymbol{b})$ denote the optimal policy function for the representative fiscal authority in the symmetric equilibrium. The monetary authority's policy function is denoted $\Pi(\boldsymbol{b})$, where we incorporate in the notation that monetary policy is driven by aggregate states alone and does not respond to idiosyncratic deviations from the symmetric equilibrium.

The individual fiscal authority faces an equilibrium interest rate schedule denoted $r(b, \boldsymbol{b})$. The interest rate depends on the first argument via the risk of default and the latter argument via anticipated inflation. In the current environment we abstract from rollover crises and focus on perfect-foresight equilibria. Lenders will not purchase bonds if default is perfectly anticipated, and thus fiscal authorities will have debt correspondingly rationed. From the lender's perspective, the real return on government bonds absent default is $r(b, \boldsymbol{b})-\Pi(\boldsymbol{b})$, which must equal $\rho$ in equilibrium. ${ }^{12}$ In the deterministic case, there is no interest rate that supports bond purchases if the government will default. Let $\bar{\Omega} \subset[0, \infty)$ denote the endogenous domain of debt stocks that can be issued in equilibrium. ${ }^{13}$

Each fiscal authority takes the inflation policy function of the monetary authority $\Pi(\boldsymbol{b})$ as given, as well as the consumption policy functions of the other members of the union, which we distinguish using a tilde, $\tilde{C}(b, \boldsymbol{b})$. Given an initial state $(b, \boldsymbol{b}) \in \bar{\Omega} \times \bar{\Omega} \times \bar{\Omega}=\bar{\Omega}^{3}$ and facing an interest rate schedule $r(b, \boldsymbol{b})$ and domain $\bar{\Omega}$, we can express the fiscal authority's

\footnotetext{
${ }^{12}$ To expand on this break-even condition, consider a bond purchased in period $t$ that matures in period $t+m$ and carries a fixed interest rate $r_{t}=r(b(t), \boldsymbol{b}(t))$. The nominal return of this bond is $e^{r_{t} m}$. Equilibrium requires that the real return per unit time is $\rho$ :

$$
\left(\frac{P(t)}{P^{e}(t+m)}\right) e^{r_{t} m}=e^{\rho m},
$$

where superscript $e$ denotes equilibrium expectations. Taking logs of both sides, dividing by $m$, letting $m \rightarrow 0$, and using the definition that $\pi^{e}(t)=\lim _{m \downarrow 0} \frac{\ln P^{e}(t+m)-\ln P(t)}{m}$, gives the condition $r_{t}=\rho+\pi^{e}(t)$. In equilibrium, $\pi^{e}(t)=\Pi\left(\boldsymbol{b}_{H}(t), \boldsymbol{b}_{L}(t)\right)$, which gives the expression in the text.

${ }^{13}$ More specifically, let $D(b, \boldsymbol{b})$ denote the default policy function, with $D(b, \boldsymbol{b})=1$ if the fiscal authority defaults and zero otherwise. The additive separability in $U$ implies that the optimal default decision of an idiosyncratic fiscal authority is independent of inflation, and hence aggregate debt. Therefore, $\bar{\Omega}=$ $\{b \mid D(b, \boldsymbol{b})=0\}$ does not depend on the aggregate states. The restriction that $b \geq 0$ is not restrictive in our environment, as no fiscal authority has an incentive to accumulate net foreign assets.
} 
problem in sequential form. For any initial debt $b \in \bar{\Omega}$ :

$$
\begin{aligned}
V(b, \boldsymbol{b}) & =\max _{c(t)} \int_{0}^{\infty} e^{-\rho t}\left(u(c(t))-\psi_{0} \Pi(\boldsymbol{b}(t))\right) d t \\
& \text { subject to } \\
\dot{b}(t) & =c(t)-y+[r(b(t), \boldsymbol{b}(t))-\Pi(\boldsymbol{b}(t))] b(t) \text { with } b(0)=b \\
\dot{\boldsymbol{b}}_{j}(t) & =\tilde{C}\left(\boldsymbol{b}_{j}(t), \boldsymbol{b}(t)\right)-y+\left[r\left(\boldsymbol{b}_{j}(t), \boldsymbol{b}(t)\right)-\Pi(\boldsymbol{b}(t))\right] \boldsymbol{b}_{j}(t), \text { for } j=H, L \\
b(t) & \in \bar{\Omega}, t \geq 0 .
\end{aligned}
$$

As we shall see, the equilibrium $\bar{\Omega}$ defines the domain on which the government does not default. Therefore, it is not restrictive to write the problem for $b \in \bar{\Omega}$ under the premise the government does not default. The equilibrium value of default given aggregate state $\boldsymbol{b}$ is given by $\underline{V}(\boldsymbol{b})=\frac{u((1-\chi) y)}{\rho}-\psi_{0} \int_{0}^{\infty} e^{-\rho t} \Pi(\boldsymbol{b}(t)) d t$, where $\boldsymbol{b}_{j}(t), j=H, L$, follow the equilibrium evolution equations stated above.

Note that the aggregate state enters the fiscal authority's problem only through the cost of inflation and the term $r(b, \boldsymbol{b})-\Pi(\boldsymbol{b})$. The latter is equal to $\rho$ in equilibrium. It is therefore convenient to state the value of the fiscal authority net of inflation costs, $\hat{V}=$ $V+\psi_{0} \int_{0}^{\infty} e^{-\rho t} \Pi(\boldsymbol{b}(t)) d t$, which will be independent of the aggregate state:

$$
\begin{aligned}
\hat{V}(b) & =\max _{c(t)} \int_{0}^{\infty} e^{-\rho t} u(c(t)) d t, \\
& \text { subject to } \\
\dot{b}(t) & =c(t)-y+\rho b(t) \text { with } b(0)=b \\
b(t) & \in \bar{\Omega}, t \geq 0 .
\end{aligned}
$$

Let $C(b)$ denote the associated policy function.

The monetary authority sets inflation $\pi(t)$ in every period without commitment. The decision of the monetary authority can be represented by a sequence problem where the monetary authority takes the interest rate function $r(b, \boldsymbol{b})$ and the representative fiscal authority's consumption function $C(b)$ as a primitive of the environment. For any debt level 
$\left(\boldsymbol{b}_{H}, \boldsymbol{b}_{L}\right) \in \bar{\Omega}^{2}$ the monetary authority solves the following problem:

$$
\begin{aligned}
& \left.J(\boldsymbol{b})=\max _{\pi(t) \in[0, \bar{\pi}]} \int_{0}^{\infty} e^{-\rho t}\left[\eta u\left(C\left(\boldsymbol{b}_{H}(t)\right)\right)+(1-\eta) u\left(C\left(\boldsymbol{b}_{L}(t)\right)\right)-\psi_{0} \pi(t)\right)\right] d t, \\
& \text { subject to } \\
& \dot{\boldsymbol{b}}_{j}(t)=C\left(\boldsymbol{b}_{j}(t)\right)+\left[r\left(\boldsymbol{b}_{j}(t), \boldsymbol{b}(t)\right)-\pi(t)\right] \boldsymbol{b}_{j}(t)-y \\
& \text { with } \boldsymbol{b}_{j}(0)=\boldsymbol{b}_{j} \text { for } j=H, L .
\end{aligned}
$$

Note that the monetary authority takes the equilibrium interest rate schedule $r$ as given. From the lenders' break-even constraint, we have that $r\left(\boldsymbol{b}_{j}, \boldsymbol{b}\right)=\rho+\pi^{e}$, for $j=H, L$, where $\pi^{e}$ is the lenders' expectation of inflation. In this sense the monetary authority is solving its problem taking inflationary expectations as a given. This is why the solution to the sequence problem (P2) is time consistent; the monetary authority is not directly manipulating inflationary expectations with its choice of inflation. In equilibrium, $\pi^{e}=$ $\Pi(\boldsymbol{b})$, but this equivalence is not incorporated into the monetary authority's problem as the central bank cannot credibly manipulate market expectations. This contrasts with the full-commitment Ramsey problem in which the monetary authority commits to a path of inflation at time zero and thereby selects market expectations. The solution to that problem is to set $\pi=0$ every period.

Before discussing the solution to the problem of the fiscal and monetary authorities, we define our equilibrium concept as follows.

Definition 1. A symmetric Recursive Competitive Equilibrium (RCE) is an interest rate schedule $r$ and associated domain $\bar{\Omega}$; a fiscal authority value function $\hat{V}$ and associated policy function $C$; and a monetary authority value function $J$ and associated policy function $\Pi$, such that:

(i) $\hat{V}$ is the value function for the solution to the fiscal authority's problem (P1') and $C$ is the associated policy function;

(ii) $J$ is the value function for the solution to the monetary authority's problem and $\Pi$ is the associated policy function for inflation;

(iii) Bond holders break even: $r(b, \boldsymbol{b})=\rho+\Pi(\boldsymbol{b})$ for all $(b, \boldsymbol{b}) \in \bar{\Omega}^{3}$;

(iv) $\hat{V}(b) \geq \underline{\hat{V}} \equiv \frac{u((1-\chi) y)}{\rho}$ for all $b \in \bar{\Omega}$.

The last condition imposes that default is never optimal in equilibrium. In the absence of rollover risk, there is no uncertainty and any default would be inconsistent with the lender's 
break-even requirement. As we shall see, this condition imposes a restriction on the domain of equilibrium debt levels. It also ensures that problem (P1'), which presumes no default, is consistent with equilibrium. That is, by construction the constraint $b(t) \in \bar{\Omega}$ in (P1') ensures that the government would never exercise its option to default in any equilibrium.

Equilibrium Allocations The fiscal authority's equilibrium policy sets $\dot{b}=0$ and $C(b)=$ $y-\rho b$ for all $b \in \bar{\Omega}$. This follows straightforwardly because income is constant and the discount rate is equal to the interest rate. The associated value function is $\hat{V}(b)=u(y-\rho b) / \rho$. The equilibrium domain $\bar{\Omega}$ can be determined from the condition $\hat{V}(b) \geq \underline{\hat{V}}$, which implies the maximal $\bar{\Omega}=\left[0, \frac{\chi y}{\rho}\right]$.

Turning to the monetary authority, faced with the above fiscal policy functions and the equilibrium $r\left(\boldsymbol{b}_{j}, \boldsymbol{b}\right)=\rho+\Pi(\boldsymbol{b})$ its problem becomes:

$$
\left.J(\boldsymbol{b})=\max _{\pi(t) \in[0, \bar{\pi}]} \int_{0}^{\infty} e^{-\rho t}\left[\eta u\left(y-\rho \boldsymbol{b}_{H}(t)\right)+(1-\eta) u\left(y-\rho \boldsymbol{b}_{L}(t)\right)-\psi_{0} \pi(t)\right)\right] d t
$$

subject to

$$
\dot{\boldsymbol{b}}_{j}(t)=[\Pi(\boldsymbol{b}(t))-\pi(t)] \boldsymbol{b}_{j}(t), \quad j=H, L,
$$

where the constraint substitutes $C(b)=y-\rho b$ into the debt evolution equation in (P2). Note that $\Pi(\boldsymbol{b})$ in the above problem represents the lenders' equilibrium expectations, which the monetary authority takes as given when choosing current inflation.

The associated Hamilton-Jacobi-Bellman equation is:

$$
\rho J(\boldsymbol{b})=\max _{\pi \in[0, \bar{\pi}]} \eta u\left(y-\rho \boldsymbol{b}_{H}\right)+(1-\eta) u\left(y-\rho \boldsymbol{b}_{L}\right)-\psi_{0} \pi+(\Pi(\boldsymbol{b})-\pi) \nabla J(\boldsymbol{b}) \cdot \boldsymbol{b}^{\prime},
$$

wherever $\nabla J(\boldsymbol{b})=\left(\frac{\partial J}{\partial \boldsymbol{b}_{H}}, \frac{\partial J}{\partial \boldsymbol{b}_{L}}\right)$ exists. The first order condition with respect to $\pi$ implies the policy function satisfies:

$$
\Pi(\boldsymbol{b})=\left\{\begin{array}{lll}
0 & \text { if } & \psi_{0}>-\nabla J(\boldsymbol{b}) \cdot \boldsymbol{b}^{\prime} \\
\in[0, \bar{\pi}] & \text { if } & \psi_{0}=-\nabla J(\boldsymbol{b}) \cdot \boldsymbol{b}^{\prime} \\
\bar{\pi} & \text { if } & \psi_{0}<-\nabla J(\boldsymbol{b}) \cdot \boldsymbol{b}^{\prime}
\end{array}\right.
$$

The inequalities that determine whether inflation is zero, maximal, or intermediate, have a natural interpretation. The marginal disutility of inflation is $\psi_{0}$. The perceived (ex post) gain from inflation is a reduction in real debt levels conditional on consumption. This reduction is proportional to the level of debt, and is translated into utility units via the terms $\nabla J$.

Conditional on the optimal inflation policy, as well as the equilibrium behavior of lenders 
and the fiscal authorities, the monetary authority's value function is:

$$
J(\boldsymbol{b})=\frac{\eta u\left(y-\rho \boldsymbol{b}_{H}\right)+(1-\eta) u\left(y-\rho \boldsymbol{b}_{L}\right)-\psi_{0} \Pi(\boldsymbol{b})}{\rho} .
$$

For $\boldsymbol{b}$ such that $\nabla \Pi(\boldsymbol{b})=\left(\frac{\partial \Pi}{\partial \boldsymbol{b}_{H}}, \frac{\partial \Pi}{\partial \boldsymbol{b}_{L}}\right)$ exists, this implies

$$
-\nabla J(\boldsymbol{b})=\left[\begin{array}{c}
\eta u^{\prime}\left(y-\rho \boldsymbol{b}_{H}\right) \\
(1-\eta) u^{\prime}\left(y-\rho \boldsymbol{b}_{L}\right)
\end{array}\right]+\frac{\psi_{0}}{\rho} \nabla \Pi(\boldsymbol{b}) .
$$

We can construct an equilibrium by finding a pair $(J, \Pi)$ that satisfies $(2)$ and $(3)$. There are many such pairs. The multiplicity arises because the monetary authority takes the nominal interest rate function (and hence inflation expectations) as given and chooses its best inflation response. Correspondingly, lenders' expectations are based on the monetary authority's policy function. There are many such equilibrium pairs.

One natural property is for the equilibrium to be monotonic, i.e. that $\Pi(\boldsymbol{b})$ be weakly increasing in each argument. From (4), monotonicity implies that

$$
-\nabla J(\boldsymbol{b}) \cdot \boldsymbol{b}^{\prime} \geq \eta u^{\prime}\left(y-\rho \boldsymbol{b}_{H}\right) \boldsymbol{b}_{H}+(1-\eta) u^{\prime}\left(y-\rho \boldsymbol{b}_{L}\right) \boldsymbol{b}_{L}
$$

From (2), if the right hand side is strictly greater than $\psi_{0}$, then optimal inflation is $\bar{\pi}$ in any monotone equilibrium. It is useful to define the locus of points $\left(\boldsymbol{b}_{H}, \boldsymbol{b}_{L}\right)$ that defines this region. In particular, for each $\boldsymbol{b}_{L} \in \bar{\Omega}$, let the cutoff $\boldsymbol{b}_{\pi}\left(\boldsymbol{b}_{L}\right)$ be defined by:

$$
\eta u^{\prime}\left(y-\rho \boldsymbol{b}_{\pi}\right) \boldsymbol{b}_{\pi}+(1-\eta) u^{\prime}\left(y-\rho \boldsymbol{b}_{L}\right) \boldsymbol{b}_{L}=\psi_{0} .
$$

Note that the concavity of $u$ implies that $\boldsymbol{b}_{\pi}$ is a well defined function and strictly decreasing in $\boldsymbol{b}_{L}$. We thus have:

Lemma 1. In any monotone equilibrium, $\Pi(\boldsymbol{b})=\bar{\pi}$ for $\boldsymbol{b} \in \bar{\Omega}^{2}$ such that $\boldsymbol{b}_{H}>\boldsymbol{b}_{\pi}\left(\boldsymbol{b}_{L}\right)$.

As inflation is a deadweight loss in a perfect-foresight equilibrium, the best case scenario in a monotone equilibrium is for $\pi=0$ on the complement of this set. Doing so is Pareto efficient in the sense that lenders are indifferent and both fiscal and monetary authorities prefer equilibria with lower inflation. In particular, we have:

Lemma 2. The best (Pareto efficient) monotone equilibrium has $\Pi(\boldsymbol{b})=0$ for $\boldsymbol{b} \in \bar{\Omega}^{2}$ such that $\boldsymbol{b}_{H} \leq \boldsymbol{b}_{\pi}\left(\boldsymbol{b}_{L}\right)$.

Not all monotone equilibria are characterized by a simple threshold that separates zero and maximal inflation. In particular, it is possible to construct monotone equilibria with 
$\Pi(\boldsymbol{b}) \in(0, \bar{\pi})$ for a non-trivial domain of $\boldsymbol{b}$. These equilibria, however, are Pareto dominated by the threshold equilibrium.

We collect the above in the following proposition:

Proposition 1. Define $\boldsymbol{b}_{\pi}\left(\boldsymbol{b}_{L}\right)$ from equation (5) and $\bar{\Omega}=\left[0, \frac{\chi y}{\rho}\right]$. The following is the best monotone equilibrium. For all $(b, \boldsymbol{b}) \in \bar{\Omega}^{3}$ :

(i) Consumption policy functions:

$$
C(b)=y-\rho b
$$

(ii) Inflation policy function:

$$
\Pi(\boldsymbol{b})= \begin{cases}0 & \text { if } \quad \boldsymbol{b}_{H} \leq \boldsymbol{b}_{\pi}\left(\boldsymbol{b}_{L}\right) \\ \bar{\pi} & \text { if } \quad \boldsymbol{b}_{H}>\boldsymbol{b}_{\pi}\left(\boldsymbol{b}_{L}\right)\end{cases}
$$

(iii) Interest rate schedule:

$$
r(b, \boldsymbol{b})=\left\{\begin{array}{lll}
\rho & \text { if } & \boldsymbol{b}_{H} \leq \boldsymbol{b}_{\pi}\left(\boldsymbol{b}_{L}\right) \\
\rho+\bar{\pi} & \text { if } & \boldsymbol{b}_{H}>\boldsymbol{b}_{\pi}\left(\boldsymbol{b}_{L}\right)
\end{array}\right.
$$

(iv) Value functions:

$$
\begin{aligned}
\hat{V}(b) & =\frac{u(y-\rho b)}{\rho} ; \\
V(b, \boldsymbol{b}) & = \begin{cases}\hat{V}(b) & \text { if } \quad \boldsymbol{b}_{H} \leq \boldsymbol{b}_{\pi}\left(\boldsymbol{b}_{L}\right), \\
\hat{V}(b)-\frac{\psi_{0} \bar{\pi}}{\rho} & \text { if } \quad \boldsymbol{b}_{H}>\boldsymbol{b}_{\pi}\left(\boldsymbol{b}_{L}\right) ;\end{cases}
\end{aligned}
$$

and $J(\boldsymbol{b})=\eta V\left(\boldsymbol{b}_{H}, \boldsymbol{b}\right)+(1-\eta) V\left(\boldsymbol{b}_{L}, \boldsymbol{b}\right)$.

The best monotone equilibrium is graphically depicted in figure 1 . We do so for a given $\boldsymbol{b}_{L}$ and let $\boldsymbol{b}_{H}$ vary along the horizontal axis, imposing the symmetry condition $b=\boldsymbol{b}_{H}$ for all high debtors. Given the symmetry of the environment, diagrams holding $\boldsymbol{b}_{H}$ constant and varying $\boldsymbol{b}_{L}$ have similar shapes, but with thresholds defined by the inverse of $\boldsymbol{b}_{\pi}$.

A prominent feature of this equilibrium is the discontinuity at $\boldsymbol{b}_{\pi}$ of the functions $V$ and $J$ with respect to the aggregate state $\boldsymbol{b}$. A small decrease in aggregate debt in the neighborhood above $\boldsymbol{b}_{\pi}$ leads to a discrete jump in welfare. The lack of coordination between fiscal and monetary authorities prevents the currency union from exploiting this opportunity, 
as each fiscal authority takes the aggregate level of debt as given. We now discuss this "fiscal externality" in greater detail.

\subsection{Fiscal externalities in a monetary union}

In this subsection, for expositional ease we assume all members of the monetary union have the same level of debt. In particular, we set $\eta=1$ and suppress $\boldsymbol{b}_{L}$ in the notation. Let $\boldsymbol{b}_{\pi}$ denote the solution to (5) when $\eta=1$ (that is, $\left.u^{\prime}\left(y-\rho \boldsymbol{b}_{\pi}\right) \boldsymbol{b}_{\pi}=\psi_{0}\right)$. In the next subsection, we return to the case of heterogeneity to explore the extent of disagreement about policy and composition of the monetary union.

The equilibrium described in Proposition 1 reflects the combination of lack of commitment and lack of coordination. With full commitment, the monetary authority would commit to zero inflation in every period. ${ }^{14}$ In this equilibrium, nominal interest rates would equal $\rho$. This generates the same level of consumption, but strictly higher utility for $\boldsymbol{b}_{H}>\boldsymbol{b}_{\pi}$. This is the Ramsey allocation depicted in figure 2, in which $V=u\left(y-\rho \boldsymbol{b}_{H}\right) / \rho$ for all $\boldsymbol{b}_{H}$. The figure also depicts the allocation of Proposition 1, which is denoted "MU" for monetary union. Clearly, the Ramsey allocation strictly dominates the monetary union case in the region of high inflation.

This point is reminiscent of the result in Chari and Kehoe (2007), which compares monetary unions in which the monetary authority has full commitment versus one that lacks commitment. This comparison is enriched by considering the role of coordination in an environment of limited commitment, a point to which we now turn.

Absent commitment, the members of the monetary union cannot achieve the Ramsey outcome at higher levels of debt. However, they may be able to do better than the benchmark allocation by coordinating monetary and fiscal policy, even under limited commitment. As noted above, the discontinuity in the value function at $\boldsymbol{b}_{\pi}$ represents an unexploited opportunity for a small amount of savings to generate a discrete gain in welfare. With coordinated fiscal and monetary policy, the optimal policy under limited commitment would be to reduce debt in the neighborhood above $\boldsymbol{b}_{\pi}$. Specifically, coordination makes the monetary union a fiscal union as well, and we can consider the entire region a small open economy (SOE) that faces a world real interest rate $\rho$. This environment is characterized in detail in Aguiar et al. (2012). Here we simply sketch the equilibrium so as to compare it to the solution of the monetary union (MU) and refer the reader to that paper for the details of the derivation.

Specifically, we consider the same threshold equilibrium defined in Proposition $1 .{ }^{15}$ Let $b$

\footnotetext{
${ }^{14}$ It could also use commitment to rule out default and borrow above $\chi y / \rho$, but would have no incentive to do so.

${ }^{15}$ There are other coordinated SOE equilibria. See Aguiar et al. (2012) for details.
} 
denote the debt level of the SOE, which is the only state variable. Re-using notation, let $r(b)$ be defined on $\bar{\Omega}$, and equal to $\rho$ for $b \leq \boldsymbol{b}_{\pi}$ and $\rho+\bar{\pi}$ for $b>\boldsymbol{b}_{\pi}$, where $\boldsymbol{b}_{\pi}$ is as defined above. We now sketch how the centralized fiscal and monetary authority responds to this schedule, and verify that it is indeed an equilibrium. We then contrast the resulting allocation with that depicted in figure 1.

Faced with this schedule, the unified "SOE" government solves the following problem:

$$
\begin{aligned}
& V_{E}(b)=\max _{\{\pi(t) \in[0, \bar{\pi}], c(t)\}} \int_{0}^{\infty} e^{-\rho t}\left(u\left(c(b(t))-\psi_{0} \pi(t)\right) d t,\right. \\
& \text { subject to } \\
& \dot{b}(t)=c(t)+(r(b(t))-\pi(t)) b(t)-y, \quad b(0)=b \quad \text { and } \quad b(t) \in \bar{\Omega},
\end{aligned}
$$

where the subscript $E$ refers to the value for a small open economy. Unlike the problem in the monetary union, fiscal and monetary policies are determined jointly in (P3). Therefore the impact of debt choices on inflation is internalized by the single authority.

At points where the value function is differentiable, the Bellman equation is given by,

$$
\rho V_{E}(b)=\max _{\pi(t) \in[0, \bar{\pi}], c(t)}\left\{u(c)-\psi_{0} \pi+V_{E}^{\prime}(b)(c-y+(r(b)-\pi) b)\right\}
$$

The first order conditions are:

$$
\begin{aligned}
u^{\prime}(c) & =-V_{E}^{\prime}(b), \\
\pi & = \begin{cases}0 & \text { if } \psi_{0} \geq-V_{E}^{\prime}(b) b=u^{\prime}(c) b \\
\bar{\pi} & \text { if } \psi_{0}<u^{\prime}(c) b .\end{cases}
\end{aligned}
$$

The first condition is the familiar envelope condition that equates marginal utility of consumption to the marginal disutility of another unit of debt. However, such a condition is not satisfied by the monetary authority's value function in the uncoordinated equilibrium, as seen in equation (4). In the coordinated case, there is no disagreement between monetary and fiscal authorities regarding the cost of another unit of debt. In particular, this provides the incentive for the fiscal authority to reduce debt in the neighborhood above $\boldsymbol{b}_{\pi}$ in the coordinated equilibrium.

In the region $b \in\left[0, \boldsymbol{b}_{\pi}\right]$, the $\mathrm{SOE}$, like the benchmark, faces an interest rate of $\rho$ and finds it optimal to set $c=y-\rho b$ and $\pi=0$. The consumption is optimal as the rate of time preference equals the interest rate and the latter is optimal as, by definition, $\psi_{0} \leq u^{\prime}(y-\rho b) b$ for $b \leq \boldsymbol{b}_{\pi}$. Thus $\pi=0$ satisfies the first order condition for inflation on this domain.

The distinction between a SOE and the benchmark MU allocation becomes apparent 
in the neighborhood above $\boldsymbol{b}_{\pi}$. We start with the allocation at $\boldsymbol{b}_{\pi}$. At this debt level, $V_{E}=u\left(y-\rho \boldsymbol{b}_{\pi}\right) / \rho$, which is the value achieved in the MU equilibrium. As in the MU economy, in the neighborhood above $\boldsymbol{b}_{\pi}$, a small open economy cannot credibly deliver zero inflation, as $\psi_{0}<u^{\prime}(y-\rho b)$ for $b>\boldsymbol{b}_{\pi}$. However, by saving it can do better than the MU allocation. Specifically, the SOE chooses $C_{E}(b)<y-\rho b$, where $C_{E}$ denotes the consumption policy function of the coordinated fiscal policy, and thus $\dot{b}(t)<0$. At this consumption, $\psi_{0}>u^{\prime}\left(C_{E}\right)$, and so the associated inflation remains $\Pi_{E}(b)=\bar{\pi}$, validating the jump in the equilibrium interest rate.

In the neighborhood above $\boldsymbol{b}_{\pi}$, the SOE can achieve the value $V\left(\boldsymbol{b}_{\pi}\right)$ by saving a small amount. That is, the SOE value function will be continuous at $\boldsymbol{b}_{\pi}$. As noted above, the monetary union keeps debt constant in this neighborhood as the idiosyncratic fiscal authorities do not internalize this potential jump in welfare from a small decrease in aggregate debt. There is no such externality in the coordinated case.

The precise level of consumption in the neighborhood above $\boldsymbol{b}_{\pi}$ can be determined by substituting in the envelope condition into (6) and using continuity of $V_{E}$. In particular, define $c_{E} \in\left(0, y-\rho \boldsymbol{b}_{\pi}\right)$ as the solution to:

$$
u\left(y-\rho \boldsymbol{b}_{\pi}\right)-\left(u\left(c_{E}\right)-\psi_{0} \bar{\pi}\right)=u^{\prime}\left(c_{E}\right)\left(y-c_{E}-\rho \boldsymbol{b}_{\pi}\right) .
$$

This consumption level satisfies the Bellman equation as we approach $\boldsymbol{b}_{\pi}$ from above. The left-hand side is the jump in flow utility once $\boldsymbol{b}_{\pi}$ is reached. The right-hand side is the marginal cost of reducing debt; that is, the marginal utility of consumption times $-\dot{b}$.

Along the trajectory to $\boldsymbol{b}_{\pi}$ there is no incentive for the government to tilt consumption, as its effective real interest rate is $\rho$. That is, $C_{E}(b)=c_{E}<y-\rho \boldsymbol{b}_{\pi}=C_{E}\left(\boldsymbol{b}_{\pi}\right)$ on a domain $\left(\boldsymbol{b}_{\pi}, \boldsymbol{b}^{*}\right)$, where the upper bound on this domain is given by $y-c_{E}=\rho \boldsymbol{b}^{*}$, the debt level at which $c_{E}$ no longer generates $\dot{b}(t)<0$. For debt above $\boldsymbol{b}^{*}$, the government prefers not to save towards $\boldsymbol{b}_{\pi}$ as the length of time required to reach this threshold is prohibitive.

Collecting the above points, we can characterize the SOE allocation, which is depicted in figure 2 alongside the benchmark "MU" and Ramsey economies. For $b=\boldsymbol{b}_{H} \leq \boldsymbol{b}_{\pi}$, the SOE, Ramsey, and MU economies are identical. For $b=\boldsymbol{b}_{H}>\boldsymbol{b}^{*}$, the SOE and MU economies are likewise identical, as the SOE economy finds it optimal to set $\dot{b}(t)=0$ despite having high inflation, as in the benchmark. However, there is a difference for $b=\boldsymbol{b}_{H} \in\left(\boldsymbol{b}_{\pi}, \boldsymbol{b}^{*}\right)$. Continuity at $\boldsymbol{b}_{\pi}$ places the SOE value function strictly above the MU case; however, limited commitment places SOE strictly below the Ramsey welfare. More specifically, from the envelope condition, the SOE's flat consumption policy function (panel b) is associated with a constant $V_{E}^{\prime}(b)$; that is, $V_{E}$ is linear on $\left(\boldsymbol{b}_{\pi}, \boldsymbol{b}^{*}\right)$. Moreover, this value function is continuous, 
and thus the line connects the MU value function at $\boldsymbol{b}_{\pi}$ to the MU value at $\boldsymbol{b}^{*}$. This line lies strictly above the MU value function on this domain, representing the welfare loss MU experiences from lack of coordination, but strictly below Ramsey, representing the welfare loss due to limited commitment.

The presence of fiscal externalities rationalizes the imposition of debt ceilings in a monetary union. They can be designed to correct the incentives of individual fiscal authorities and implement the SOE outcome in a monetary union by simply imposing that each member's debt is equal to (or less than) the optimal debt from the SOE problem. Of course the problem is that it is difficult to make such debt ceilings credible in the face of ex-post challenges - as illustrated by the repeated violations of the Stability and Growth Pact in the eurozone.

\subsection{Heterogeneity Absent Crises}

We conclude this section by discussing to what extent heterogeneity in debt positions creates disagreement within a monetary union. We are particularly interested in the question of whether existing members disagree about the debt choices of other members (or potential new members). The answer to this question in the current environment contrasts with the answer when rollover crises are possible in equilibrium, and so the discussion in this subsection sets the stage for a key result of the next section.

To do so, we consider $\eta \in(0,1)$. Recall that $\eta$ is the measure of high-debt members that enter with $\boldsymbol{b}_{H}>\boldsymbol{b}_{L}$. From the value functions defined in Proposition 1, all members benefit from a higher $\boldsymbol{b}_{\pi}$. From the definition of this threshold in equation (5), note that all else equal, $\boldsymbol{b}_{\pi}$ is decreasing in $\eta$ if $\boldsymbol{b}_{\pi}\left(\boldsymbol{b}_{L}\right)>\boldsymbol{b}_{L}$. This is the relevant domain, as otherwise even low debtors have high enough debt to induce maximal inflation. This implies that even high-debt members would like to see the fraction of low-debt members increase. Although high-debt members trigger high inflation ex post, they would like ex ante commitment to low inflation at the time they roll over their debt, which happens every period. This is accomplished by membership in a low-debt monetary union. In fact, for $\boldsymbol{b}_{L}<\boldsymbol{b}_{\pi}\left(\boldsymbol{b}_{L}\right)$, the Ramsey allocation is implemented as $\eta \rightarrow 0$. There is also no disagreement among the heterogeneous members that this is welfare improving. The result that high-debt countries benefit by joining a low-debt monetary union does not necessarily hold when we introduce rollover crises, the focus of the next section. 


\section{Rollover Crises}

We now enrich our setup to allow for rollover crises defined as a situation where lenders may refuse to roll over debt. This can generate default in equilibrium, unlike the analysis of section 3. The distinction between high and low debtors will be a central focus of the analysis. As in the no-crisis equilibrium from the previous section, in the equilibrium described below, countries that start with low enough debt have no debt dynamics; as we shall see, this is no longer the case for high debtors. To simplify the exposition, we set $\boldsymbol{b}_{L}=0$ and $\operatorname{drop} \boldsymbol{b}_{L}$ from the notation, as this state variable is always static in the equilibria under consideration. That is, $\boldsymbol{b}=\boldsymbol{b}_{H}$ is sufficient to characterize the aggregate state in the equilibria described below.

To introduce rollover crises, we follow Cole and Kehoe (2000) and consider coordination failures among creditors. That is, we construct equilibria in which there is no default if lenders roll over outstanding bonds, but there is default if lenders do not roll over debt. In continuous time with instantaneous bonds, failure to roll over outstanding bonds implies a stock of debt must be repaid with an endowment flow. To allow some notion of maturity in a tractable manner, we follow Aguiar et al. (2012) and assume that the debt contract provides the fiscal authority with a "grace period" of exogenous length $\delta$ during which it can repay the bonds plus accumulated interest at the interest rate originally contracted on the debt. If it repays within the grace period it returns to the financial markets in good standing. If the government fails to make full repayment within the grace period and defaults, it is punished by permanent loss of access to international debt markets plus a loss of output given by the parameter $\chi$. We continue to assume that it is not excluded from the union. ${ }^{16}$

We construct a crisis equilibrium as follows. We first consider the fiscal authority's and monetary authority's problems in the grace period when creditors refuse to roll over outstanding debt. We compute the welfare of repaying the bonds within the grace period and compare that to the welfare from outright default. This will allow us to determine whether or not a rollover crisis is possible given the state. We then define the full problem of the fiscal and monetary authorities under the threat of a rollover crisis and characterize the equilibria.

\footnotetext{
${ }^{16} \mathrm{In}$ what follows, we restrict the fiscal authority to have access to the grace period only when there is a rollover crisis. However, this is without loss of generality, as the fiscal authority would never exercise the grace period when it can roll over bonds. This property follows because all the equilibria we study have declining interest rates over time, and the fiscal authority would strictly prefer to roll over bonds at a lower rate.
} 


\subsection{The Grace Period Problem}

In this subsection, we characterize the equilibrium response to a rollover crisis. When confronted with a crisis, the government can either repay the principal due, or default. We characterize the value conditional on repayment in this subsection. Keep in mind, however, that repayment will be an off-equilibrium occurrence. The goal of the section, therefore, is to establish in which states default dominates repayment.

We continue our focus on symmetric equilibrium and thus characterize the problem for an individual country with debt $b$ and the remaining debtors having debt $\boldsymbol{b}$. This will allow us to establish the payoffs to the idiosyncratic deviation of an individual fiscal authority. Low-debt countries start with zero debt and, as a result, their consumption is given by $c=y$ and their debt remains at zero. With zero debt they are not subject to rollover crises. We therefore focus on high-debt countries.

We assume that when a fiscal authority is faced with a run on its debt, it cannot issue new bonds to repay maturing bonds. As discussed above, the fiscal authority has the option of repaying all debt within the grace period of length $\delta$ or defaulting. When making its decision, the individual fiscal authority takes the policies of the other fiscal authorities and the monetary authority as given. However, the payoff to repayment depends on these other policies, which in turn depends on whether the other fiscal authorities are themselves subject to a rollover crisis.

In the grace period problem, the government is obligated to repay the nominal balance on or before date $\delta$, with interest accruing over the grace period at the original contracted rate $\tilde{r} .{ }^{17}$ To set notation, we normalize $t=0$ at the start of the grace period. The fiscal authority's repayment problem depends on the amount of debt outstanding as well as the contracted interest rate, $\tilde{r}$. Let $s \equiv(b, \tilde{r})$ denote these individual states. The repayment problem also depends on the inflation policy of the central bank during the grace period, which we denote by the function $\tilde{\Pi}:[0, \delta] \rightarrow[0, \bar{\pi}]$.

\footnotetext{
${ }^{17}$ As in Aguiar et al. (2012) we impose the pari passu condition that all bond holders have equal standing; that is, the fiscal authority cannot default on a subset of bonds, while repaying the remaining bondholders. Therefore, the relevant state variable is the entire stock of outstanding debt at the time the fiscal authority enters the grace period.
} 
Let $\hat{V}^{G}$ denote the value of repayment within the grace period net of inflation costs:

$$
\begin{aligned}
\hat{V}^{G}(s ; \tilde{\Pi}) & =\max _{c(t)} \int_{0}^{\delta} e^{-\rho t} u(c(t)) d t+e^{-\rho \delta} \hat{V}(0), \\
\text { subject to } & \\
\dot{b}(t) & =c(t)-y+[\tilde{r}-\tilde{\Pi}(t)] b(t), \\
b(0) & =b, \quad b(\delta)=0, \quad \text { and } \quad \dot{b}(t) \leq-\tilde{\Pi}(t) b(t) .
\end{aligned}
$$

The term $\hat{V}(0)$ in the objective function represents the equilibrium value of returning to the markets with zero debt at the end of the grace period. The constraint $\dot{b}(t) \leq-\tilde{\Pi}(t) b(t)$ imposes that no new nominal bonds be issued, that is $\dot{B}(t) \leq 0$.

The value $\hat{V}^{G}$ is decreasing in the individual fiscal authority's debt $b$ and interest rate $\tilde{r}$ because both increase the real amount to be repaid over the grace period given inflation. The optimal path of consumption during the grace period is denoted by $C^{G}(s, t ; \tilde{\Pi})$.

The fiscal authority will choose to default when $\hat{V}^{G}<\underline{\hat{V}}$ and repay when $\hat{V}^{G} \geq \underline{\hat{V}}$. Note that the direct utility costs of inflation do not enter into the decision to default in a crisis. These costs are borne regardless of the individual fiscal authority's decision. However, inflation also enters into the budget constraint (7). Higher inflation relaxes this constraint making it easier for the fiscal authority to repay its debt quickly. This is not offset by a higher (post-crisis) interest rate, as the fiscal authority is not rolling over its debt at a new interest rate. Therefore, a fiscal authority facing a crisis will find repayment relatively attractive the more accommodating is monetary policy.

\subsection{Rollover Crises}

Having characterized the equilibrium best response to a rollover crisis, we explore how runs occur in equilibrium. The key consideration is whether, in the event of a run, the fiscal authority finds it optimal to default or repay within the grace period. The run can be supported in equilibrium if the fiscal authority's best response is to default.

To see why this reflects a coordination failure, consider an individual creditor's problem when all other creditors refuse to purchase new debt. If $\hat{V}^{G}<\underline{\hat{V}}$, then the best response of the fiscal authority to the rollover crisis is to default. An individual creditor that purchases new bonds is not large enough to alter this decision and thus will receive zero in return for any bonds it purchases. Thus, it is individually optimal for the creditor to also refuse to purchase new bonds.

While a run may be sustained at a particular level of debt, it is not the only equilibrium outcome possible. Absent a run, the fiscal authority may be willing to service the debt 
as usual, paying off maturing bonds by issuing new bonds. Moreover, as discussed in the previous subsections, the response of an individual fiscal authority depends on the actions of the monetary authority, which in turn depends on the fraction $\eta$ of other members in crisis.

To incorporate this multiplicity and interdependence in a tractable manner, we extend the environment of Cole and Kehoe (2000), which considers the case of a small open economy. Specifically, the equilibrium will define a region of the debt state space in which a fiscal authority is vulnerable to a rollover crisis. Following Cole and Kehoe, we shall refer to this region as the crisis region. To characterize a symmetric equilibrium, this region needs to be defined over two dimensions- the own debt of an individual fiscal authority and the debt of the representative fiscal authority. We hew as closely as possible to the single-country case of Cole and Kehoe (2000) by considering a simple threshold $\boldsymbol{b}_{\lambda}$, such that an individual debtor with debt $b \in \bar{\Omega}$ is vulnerable to a crisis if $b>\boldsymbol{b}_{\lambda}$, regardless of the debt level of the other members $\boldsymbol{b}$. We shall refer to the set $\mathbb{C} \equiv\left\{b \in \bar{\Omega} \mid b>\boldsymbol{b}_{\lambda}\right\}$ as the "crisis zone," and its complement in $\bar{\Omega}$ as the "safe zone."

Also following Cole and Kehoe (2000), we introduce a sunspot that coordinates creditor beliefs. Specifically, if $b \in \mathbb{C}$, then with Poisson arrival $\lambda$ creditors refuse to roll over maturing debt and the fiscal authority defaults. Let $\mathbb{I}_{\mathbb{C}}(b)$ denote an indicator function that takes the value one if $b \in \mathbb{C}$ and zero otherwise. Let $T$ denote the first arrival of a rollover crisis. Given a path of debt $b(t)$, the probability that $T>\tau$ is therefore,

$$
\operatorname{Pr}(T>\tau)=e^{-\lambda \int_{0}^{\tau} \mathbb{I}_{\mathbb{C}}(b(t)) t d t}
$$

The realization of $T$ is public information and it is the only uncertainty in the model.

\subsection{Fiscal Authorities}

We now state the problem of the fiscal authority prior to a rollover crisis. As before, the government takes as given an equilibrium interest rate schedule $r(b, \boldsymbol{b})$, a debt domain $\bar{\Omega}$, and a monetary policy function $\Pi$. The new equilibrium object is $\mathbb{C}$. In equilibrium, lenders receive an expected real return of $\rho$. That is, the nominal interest rate compensates lenders for expected default as well as expected inflation:

$$
r(b, \boldsymbol{b})=\rho+\Pi(\boldsymbol{b})+\lambda \mathbb{I}_{\mathbb{C}}(b),
$$

for $(b, \boldsymbol{b}) \in \bar{\Omega}^{2}$. 
The government's problem (net of inflation costs) is:

$$
\begin{aligned}
& \hat{V}(b)=\max _{c(t)} \int_{0}^{\infty} e^{-\rho t-\lambda \int_{0}^{t} \mathbb{I}_{\mathbb{C}}(b(s)) d s}[u(c(t))+\lambda \underline{\hat{V}}] d t \\
& \quad \text { subject to } \\
& \dot{b}(t)=c(t)-y+\left[\rho+\lambda \mathbb{I}_{\mathbb{C}}(b(t))\right] b(t), \quad b(0)=b \quad \text { and } \quad b(t) \in \bar{\Omega},
\end{aligned}
$$

where we have used (8) to substitute $\rho+\lambda \mathbb{I}_{\mathbb{C}}(b)$ for $r(b, \boldsymbol{b})-\Pi(\boldsymbol{b})$ in the debt evolution equation. The objective function captures the fact that the fiscal authority consumes $c(t)$ as long as it has not been hit by a rollover crisis, and in the event of a rollover crisis it receives value $\hat{\underline{V}}$. We denote by $C(b)$ the policy function for consumption associated with the planning problem (P4).

An important difference between (P4) and its non-crisis counterpart in (P1') is the fact that the interest rate now depends on individual debt through $\mathbb{I}_{\mathbb{C}}$. In particular, the fiscal authority can reduce its rate by saving its way out of the crisis zone. As we show below this incentive gives rise to a "saving zone" within the crisis zone where fiscal authorities reduce their debt over time and a "staying zone" where they keep their debt constant.

\subsection{Monetary Authority}

The problem of the monetary authority when the representative fiscal authority with debt $\boldsymbol{b}$ is not in a crisis is:

$$
\begin{aligned}
J(\boldsymbol{b}) & =\max _{\pi(t)} \int_{0}^{\infty} e^{-\rho t-\lambda \int_{0}^{t} \mathbb{I}_{\mathbb{C}}(b(s)) d s} \eta[u(C(\boldsymbol{b}(t))+\lambda \underline{\hat{V}}] d t \\
& +\int_{0}^{\infty}(1-\eta) e^{-\rho t} u(y)-\psi_{0} \int_{0}^{\infty} e^{-\rho t-\lambda \int_{0}^{t} \mathbb{I}_{\mathbb{C}}(b(s)) d s} \pi(t) d t, \\
& \text { subject to } \\
\dot{\boldsymbol{b}}(t) & =C(\boldsymbol{b}(t))-y+[r(\boldsymbol{b}(t), \boldsymbol{b}(t))-\pi(t)] \boldsymbol{b}(t) \\
& =C(\boldsymbol{b}(t))-y+\left[\rho+\Pi(\boldsymbol{b}(t))+\lambda \mathbb{I}_{\mathbb{C}}(\boldsymbol{b}(t))-\pi(t)\right] \boldsymbol{b}(t), \\
& \text { and } \boldsymbol{b}(0)=\boldsymbol{b} .
\end{aligned}
$$

The objective function takes into account the welfare of both high-debt and low-debt fiscal authorities with weights $\eta$ and $(1-\eta)$ respectively. The monetary authority takes as given the consumption policy function of the representative fiscal authority with debt $\boldsymbol{b}$, which varies depending on whether it has been hit by the crisis shock or not. The consumption 
of the low-debt fiscal authority is always equal to $y$. As long as the representative fiscal authority is not in default, that is as long as it has not been hit by the crisis shock, the monetary authority is tempted to inflate so as to reduce the real value of debt to be repaid, thereby raising consumption and helping the fiscal authority exit the crisis zone. When the representative fiscal authority is hit by the crisis shock and defaults, the monetary authority sets inflation to zero as there is no benefit from inflating when there is zero debt. We denote by $\Pi(\boldsymbol{b})$ the policy function for inflation associated with the planning problem (P5).

\subsection{Crisis Equilibrium}

Before defining equilibrium with self-fulfilling crises, we discuss how inflation expectations are formed at the onset of a crisis. The fiscal authority's grace period problem (PG) is defined conditional on an expected inflation policy $\tilde{\Pi}$. These expectations depend on whether other debtors are facing crisis; that is, whether $\boldsymbol{b}>\boldsymbol{b}_{\lambda}$. In a symmetric equilibrium, all debtors are identical and will face the crisis together. However, to define equilibrium, we also need to consider the case of an individual country that deviates from the representative debt level.

If the representative debtor has $\boldsymbol{b}>\boldsymbol{b}_{\lambda}$, then all debtors will face a rollover crisis simultaneously. In equilibrium, the representative debtor defaults, and therefore $\tilde{\Pi}=0$ as the monetary authority has no incentive to inflate after default.

If the representative debtor has $\boldsymbol{b} \leq \boldsymbol{b}_{\lambda}$ at the start of the crisis, then the representative debtor does not face a rollover crisis. In this case, $\tilde{\Pi}(t)=\Pi(\boldsymbol{b}(t))$, the non-crisis inflation policy, where $\boldsymbol{b}(t)$ is the aggregate state $t$ periods after the start of the crisis.

Collecting these points, we define the expected inflation in a crisis by:

$$
\tilde{\Pi}^{e}(t, \boldsymbol{b})=\left\{\begin{array}{l}
0 \text { if } \boldsymbol{b}>\boldsymbol{b}_{\lambda} \\
\Pi(\boldsymbol{b}(t)) \text { if } \boldsymbol{b} \leq \boldsymbol{b}_{\lambda}
\end{array}\right.
$$

where $\boldsymbol{b}(t)$ solves the debt evolution equation from problem $(\mathrm{P} 4)$ starting from $\boldsymbol{b}(0)=\boldsymbol{b}$. An equilibrium condition will be that $V^{G}$ is evaluated at $\tilde{\Pi}=\tilde{\Pi}^{e}(\cdot, \boldsymbol{b})$.

We now state the definition of equilibrium with crises:

Definition 2. A Recursive Competitive Equilibrium with Crises specifies an interest rate schedule $r$ with domain $\bar{\Omega}$, consumption functions $C$ and $C^{G}$, inflation policy function $\Pi$, value functions $\hat{V}, \hat{V}^{G}$ for the fiscal authorities, and $J$ for the monetary authority, as well as a threshold $\boldsymbol{b}_{\lambda}$, such that for $(b, \boldsymbol{b}) \in \bar{\Omega}^{2}$ :

(i) $\hat{V}$ solves the fiscal authority's problem (P4) and $C$ is the associated policy function; 
(ii) $\hat{V}^{G}$ solves the fiscal authority's grace period problem $(\mathrm{PG})$ and $C^{G}$ is the associated policy function when $\tilde{r}=r(b, \boldsymbol{b})$ and $\tilde{\Pi}=\tilde{\Pi}^{e}(\cdot, \boldsymbol{b})$ defined in $(10)$;

(iii) J solves the monetary authority's problem (P5) and $\Pi$ is the associated policy function;

(iv) Bond holders earn a real return $\rho$, that is $r(b, \boldsymbol{b})=\rho+\Pi(\boldsymbol{b})+\lambda \mathbb{I}_{\mathbb{C}}(b)$;

(v) $\hat{V}(b) \geq \underline{\hat{V}}$; and

(vi) $\hat{V}^{G}\left(b, r(b, \boldsymbol{b}) ; \tilde{\Pi}^{e}(\cdot, \boldsymbol{b})\right)<\underline{\hat{V}}$ for $b>\boldsymbol{b}_{\lambda}$ and all $\boldsymbol{b} \in \bar{\Omega}$.

Condition (vi) ensures that a rollover crisis is consistent with equilibrium behavior. Specifically, if a country is subject to a run on its debt, it will decide to default rather than repay within the grace period. Given that the crisis region for a country does not depend on the aggregate state, this must be true regardless of the representative country's debt position.

In what follows, we restrict attention to monotone equilibria where the inflation policy follows a threshold rule (as was the case in the best monotone equilibrium without crises). We will refer to these equilibria as monotone equilibria with thresholds. Among these, just as in the case with no crisis, we analyze the one with the best possible inflation threshold. We first characterize this equilibrium for a given $\boldsymbol{b}_{\lambda}$, and then discuss the determination of the crisis threshold.

\subsection{Equilibrium Policies}

\section{Fiscal Authority}

The fiscal authority's problem is stated in equation $(\mathrm{P} 4)$. The value function satisfies the following Hamilton-Jacobi-Bellman equation:

$$
\left(\rho+\lambda \mathbb{I}_{\mathbb{C}}(b)\right) \hat{V}(b)=\max _{c}\left\{u(c)+\hat{V}^{\prime}(b)\left[\left(\rho+\lambda \mathbb{I}_{\mathbb{C}}(b)\right) b+c-y\right]+\lambda \mathbb{I}_{\mathbb{C}}(b) \underline{\hat{V}}\right\}
$$

whenever $\hat{V}$ is differentiable at $b$, where we have used condition (iv) from the definition of equilibrium to substitute out the equilibrium interest rate. The first order condition for the fiscal authority is $u^{\prime}(c)=-\hat{V}^{\prime}(b)$. 
The solution $\hat{V}$ for $b \in \bar{\Omega}$ is: ${ }^{18}$

$$
\hat{V}(b)= \begin{cases}\frac{u(y-\rho b)}{\rho} & \text { if } b \leq \boldsymbol{b}_{\lambda}, \\ \hat{V}\left(\boldsymbol{b}_{\lambda}\right)-u^{\prime}\left(c_{\lambda}\right)\left(b-\boldsymbol{b}_{\lambda}\right) & \text { if } \boldsymbol{b}_{\lambda}<b \leq b^{*} \\ \frac{u(y-(\rho+\lambda) b)}{\rho+\lambda}+\frac{\lambda}{\rho+\lambda} \hat{V} & \text { if } b^{*}<b,\end{cases}
$$

where $c_{\lambda} \in\left(0, y-(\rho+\lambda) \boldsymbol{b}_{\lambda}\right)$ is the solution to:

$$
\frac{(\rho+\lambda)}{\rho} u\left(y-\rho \boldsymbol{b}_{\lambda}\right)-\left(u\left(c_{\lambda}\right)+\lambda \underline{\hat{V}}\right)=u^{\prime}\left(c_{\lambda}\right)\left(y-c_{\lambda}-(\rho+\lambda) \boldsymbol{b}_{\lambda}\right),
$$

and $b^{*}=\left(y-c_{\lambda}\right) /(\rho+\lambda)$. The associated consumption policy function is:

$$
C(b)=\left\{\begin{array}{l}
y-\rho b \text { if } b \leq \boldsymbol{b}_{\lambda} \\
c_{\lambda} \text { if } \boldsymbol{b}_{\lambda}<b \leq b^{*} \\
y-(\rho+\lambda) b \text { if } b^{*}<b .
\end{array}\right.
$$

The consumption function implies the following for debt dynamics:

$$
\dot{b}=\left\{\begin{array}{l}
-(\rho+\lambda)\left(b^{*}-b\right) \text { if } b \in\left(\boldsymbol{b}_{\lambda}, b^{*}\right) \\
0 \text { otherwise }
\end{array}\right.
$$

We now discuss why the solution takes this form.

If $b \notin \mathbb{C}$, the country is not vulnerable to a rollover crisis. With initial debt in the safe zone, the solution to the fiscal authority's problem is the same as that of problem (P1') described in the no-crisis equilibrium (Section 3). In particular, consumption maintains a stationary debt level, $C(b)=y-\rho b$. The individual fiscal authority has no incentive to save in this region.

For $b \in \mathbb{C}$, the fiscal authority does have an incentive to save. The fiscal authority can eliminate the probability of default and the associated premium $\lambda$ in its interest rate by reducing debt to $\boldsymbol{b}_{\lambda}$. In contrast to reducing the incentive to inflate, which depends on aggregate debt, there is no fiscal externality when it comes to reducing idiosyncratic default risk.

The speed at which they save is governed by the Bellman equation (11). Specifically, equation (13) is the Bellman equation evaluated as $b$ approaches $\boldsymbol{b}_{\lambda}$ from above, using the knowledge of $\hat{V}\left(\boldsymbol{b}_{\lambda}\right)$ at the boundary of the safe zone plus the fact that $\hat{V}$ is continuous.

\footnotetext{
${ }^{18}$ See Aguiar et al. (2012) for the appropriate solution procedure to Hamilton-Jacobi-Bellman equations of this type, including how to address points of non-differentiability.
} 
Equation (13) determines the optimal consumption $c_{\lambda}$ in the neighborhood above $\boldsymbol{b}_{\lambda}$.

While the fiscal authority saves, it has no incentive to tilt consumption over time. That is, it discounts at $\rho+\lambda$, which is the real interest rate on its debt in the crisis zone. In particular, consumption is constant for a range of $b$ as the fiscal authority saves towards the safe zone. From the first order condition, $u^{\prime}(c)=-\hat{V}^{\prime}(b)$, constant consumption implies linearity in $\hat{V}$.

Starting from high enough debt, the cost of saving to $\boldsymbol{b}_{\lambda}$ is prohibitively high. In particular, at $b^{*}=\left(y-c_{\lambda}\right) /(\rho+\lambda)$, the fiscal authority will not exit the crisis region in finite time while consuming $c_{\lambda}$. As a result, for $b \geq b^{*}$ it prefers to remain in the crisis region indefinitely. In this region, $\hat{V}$ takes the stationary-debt value when the real interest rate is $\rho+\lambda$ and it faces a constant hazard $\lambda$ of default.

\section{Monetary Authority}

The monetary authority's problem is stated in (P5). The associated Hamilton-JacobiBellman equation, where $J$ is differentiable, is:

$$
\begin{aligned}
\left(\rho+\lambda \mathbb{I}_{\mathbb{C}}(\boldsymbol{b})\right) J(\boldsymbol{b}) & =\max _{\pi \in[0, \bar{\pi}]}\left\{\eta u(C(\boldsymbol{b}))+(1-\eta) u(y)-\psi_{0} \pi\right. \\
& \left.+J^{\prime}(\boldsymbol{b})[(r(\boldsymbol{b})-\pi) \boldsymbol{b}+C(\boldsymbol{b})-y]+\lambda \mathbb{I}_{\mathbb{C}}(\boldsymbol{b}) \underline{J}\right\},
\end{aligned}
$$

where $\underline{J} \equiv \eta \underline{V}+(1-\eta) \frac{u(y)}{\rho}$ is the monetary authority's value post crisis. The first order conditions imply that optimal inflation is zero if $-J^{\prime}(\boldsymbol{b}) \boldsymbol{b} \leq \psi_{0}$, and $\bar{\pi}$ otherwise.

By definition, the best equilibrium with thresholds sets inflation to zero over the largest possible debt domain. We therefore look for the largest $b$ such that $-J^{\prime}(\boldsymbol{b}) \boldsymbol{b} \leq \psi_{0}$. We continue to denote the threshold for inflation as $\boldsymbol{b}_{\pi}$, as in the non-crisis benchmark.

A useful insight in defining the inflation threshold is that in the interior of the domain where inflation is zero, $J^{\prime}(\boldsymbol{b})=\eta \hat{V}^{\prime}(\boldsymbol{b})$. To see this, from the solution to the fiscal authority's problem, we have $\boldsymbol{b} \leq 0$ in equilibrium. Therefore, if $\boldsymbol{b} \leq \boldsymbol{b}_{\pi}$, inflation is always zero. This implies that $V(\boldsymbol{b})=\hat{V}(\boldsymbol{b})$ for $\boldsymbol{b} \leq \boldsymbol{b}_{\pi}$. Recall that the monetary authority's value is the weighted sum of $V$ and the constant $u(y) / \rho$ (when inflation is zero). It follows then that $J^{\prime}(\boldsymbol{b})=\eta \hat{V}^{\prime}(\boldsymbol{b})$ when $\boldsymbol{b} \leq \boldsymbol{b}_{\pi}$.

The first order condition from the fiscal authority's problem then implies that $-J^{\prime}(\boldsymbol{b})=$ $\eta u^{\prime}(C(\boldsymbol{b}))$ on the zero-inflation domain, where $C$ is the fiscal authority's policy function given by (14). This leads to the following, which is proved in Appendix B: 
Proposition 2. Conditional on $\boldsymbol{b}_{\lambda}$, the largest possible inflation threshold is such that:

$$
\boldsymbol{b}_{\pi}=\sup _{b}\left\{b \in \bar{\Omega} \mid u^{\prime}(C(b)) b \leq \frac{\psi_{0}}{\eta}\right\} .
$$

Note that as $C(b)$ is weakly decreasing in $b$ and left continuous, definition (17) implies that $-J^{\prime}(\boldsymbol{b}) \boldsymbol{b} \leq \psi_{0}$ for all $\boldsymbol{b} \leq \boldsymbol{b}_{\pi}$. That is, on this domain zero inflation is the monetary authority's best response to the fiscal authority's policy and expectations of zero inflation. Appendix B demonstrates that zero inflation is not sustainable above $\boldsymbol{b}_{\pi}$. Appendix B also provides an analytical characterization of the monetary authority's value function.

The associated inflation policy function is:

$$
\Pi(\boldsymbol{b})=\left\{\begin{array}{l}
0 \text { if } \boldsymbol{b} \leq \boldsymbol{b}_{\pi} \\
\bar{\pi} \text { if } \boldsymbol{b}_{\pi}<\boldsymbol{b},
\end{array}\right.
$$

and, the lenders' break-even condition implies:

$$
r(b, \boldsymbol{b})=\rho+\Pi(\boldsymbol{b})+\lambda \mathbb{I}_{\mathbb{C}}(b) .
$$

The preceding characterizes the equilibrium for a given crisis threshold $\boldsymbol{b}_{\lambda}$. We now turn to the determination of this equilibrium threshold.

\subsection{The Equilibrium Crisis Zone}

There are many crisis equilibria corresponding to different thresholds $\boldsymbol{b}_{\lambda}$. Condition (vi) in the equilibrium definition requires that $\hat{V}^{G}<\underline{\hat{V}}$ in the crisis zone. However, it does not place

restrictions on the value of $\hat{V}^{G}-\underline{\hat{V}}$ in the safe zone. Moreover, it does not place restrictions on the off-equilibrium beliefs about $\tilde{\Pi}$ if a crisis were to arrive when debtors are in the safe zone. That is, if a crisis were to occur in the safe zone, at what $\tilde{\Pi}$ do we evaluate $\hat{V}^{G}$ ? We now propose beliefs that yield a unique threshold, and then motivate this equilibrium selection.

Specifically, consider the scenario in which all debtors are facing a crisis, and the monetary authority optimally sets inflation assuming that the debtors will repay within the grace period. This provides crisis debtors with the maximal inflationary support for repayment that is consistent with the monetary authority's objective function. In particular, conditional on the state $\boldsymbol{s}=(\boldsymbol{b}, \tilde{\boldsymbol{r}})$ and the inflation expectations of the fiscal authorities $\tilde{\Pi}$, the monetary authority solves the following grace period problem: 


$$
\begin{aligned}
J^{G}(\boldsymbol{s} ; \tilde{\Pi}) & =\max _{\pi(t) \in[0, \tilde{\pi}]} \int_{0}^{\delta} e^{-\rho t}\left(\eta u\left(C^{G}(\boldsymbol{s}, t ; \tilde{\Pi})+(1-\eta) u(y)-\psi_{0} \pi(t)\right) d t+\frac{e^{-\rho \delta}}{\rho} J(0),\right. \\
\text { subject to } & \\
\dot{\boldsymbol{b}}(t) & =C^{G}(\boldsymbol{s}, t ; \tilde{\Pi})-y+[\tilde{\boldsymbol{r}}-\pi(t)] \boldsymbol{b}(t), \quad \boldsymbol{b}(0)=\boldsymbol{b},
\end{aligned}
$$

where $J(0)$ is the monetary authority's value at the end of the grace period (when all members have zero debt). Let $\Pi^{G}(s)$ denote the policy function associated with this problem.

The value function $J^{G}(\boldsymbol{s})$ is decreasing in $\boldsymbol{b}$ and $\tilde{\boldsymbol{r}}$, because both increase the required debt repayment by the representative fiscal authority in the grace period. The objective function of the monetary authority and the fiscal authority differ because the former maximizes aggregate welfare and recognizes that only a fraction $\eta$ of countries have positive levels of debt. Consequently the benefits from inflating are restricted to this $\eta$ fraction of countries. For a given $(\boldsymbol{b}, \tilde{\boldsymbol{r}})$, the monetary authority is more likely to inflate the larger the fraction of countries with positive debt, i.e., the higher is $\eta$.

The monetary authority's problem takes the inflation expectations implicit in the fiscal authority's $C^{G}$ as given. Consistency requires that $\tilde{\Pi}=\Pi^{G}$. In contrast to the on-equilibrium inflation policy, the fact that the monetary authority takes the fiscal authority's expectations as given does not lead to inefficiency in the grace period problem. This is due to the fact that the interest rate is independent of policy once the debtor enters the grace period, as all debt is legacy debt contracted before the crisis. This implies that in a crisis, a coordinated monetary-fiscal response can be implemented in equilibrium. We expand on this point in Appendix A.

We now define our equilibrium threshold:

$$
\boldsymbol{b}_{\lambda}=\sup \left\{\boldsymbol{b} \in \bar{\Omega} \mid \hat{V}^{G}\left(\boldsymbol{b}, r(\boldsymbol{b}, \boldsymbol{b}) ; \Pi^{G}\right) \geq \underline{\hat{V}}\right\}
$$

This threshold corresponds to the maximal debt the government is willing to repay within the grace period at the equilibrium interest rate, conditional on other debtors not defaulting and monetary policy behaving accordingly.

We motivate this threshold as follows. In Appendix $A$, we formally show that in the grace period there is no fiscal externality. That is, if all countries are symmetric and if fiscal and monetary decisions for all countries are delegated to a central authority, then in the grace period, this authority would implement exactly the same allocation as that reached in an equilibrium with independent fiscal authorities.

Despite the absence of the traditional fiscal externality in the grace period, there remains 
a "default externality." The default externality arises because there may be more than one equilibrium best response from the monetary union. If the fiscal authorities default, the monetary authority will not inflate thus making repayment difficult. Conversely, an alternative equilibrium response may exist in which fiscal authorities repay within the grace period, aided by accommodative monetary policy.

While the default externality may be of interest in some contexts, it is not robust to a straightforward coordination of beliefs among members of the monetary union. In Appendix $A$, we show that if all countries are symmetric and if default, fiscal and monetary decisions for all countries are delegated to a central authority, then faced with a rollover crisis, the allocation implemented by this authority can also be reached when default and fiscal decisions are made by independent fiscal authorities. That is, during the grace period, the monetary union can achieve the single-decision-maker outcome by coordinating beliefs on the preferable response. $^{19}$

Our equilibrium selection imposes the requirement that if there exists an equilibrium best response in which the monetary authority comes to the rescue of the fiscal authorities in a crisis by generating high inflation, the fiscal authorities proceed as if they will be rescued. This selection is appealing given the plausibility that beliefs within the union can be coordinated in this way. Given these off-equilibrium beliefs, the threshold defined in (20) generates the largest possible crisis zone.

The threshold defined in (20) is conditional on an equilibrium interest rate schedule. Recall from the derivation of (17) that in any equilibrium, for $\boldsymbol{b} \leq \boldsymbol{b}_{\lambda}$ we have $J^{\prime}(\boldsymbol{b})=$ $\eta \hat{V}^{\prime}(\boldsymbol{b})=-\eta u^{\prime}(y-\rho \boldsymbol{b})$. Therefore, for $\boldsymbol{b} \leq \boldsymbol{b}_{\lambda}$, inflation will be zero if $u^{\prime}(y-\rho \boldsymbol{b}) \boldsymbol{b} \leq \psi_{0} / \eta$ and $\bar{\pi}$ otherwise. This implies that $r(\boldsymbol{b}, \boldsymbol{b})$ in equation (20) can be replaced by

$$
\rho+\bar{\pi} \mathbb{I}\left\{u^{\prime}(y-\rho \boldsymbol{b}) \boldsymbol{b}>\psi_{0} / \eta\right\}
$$

where $\mathbb{I}\{x\}$ is the indicator function that takes the value one if $x$ is true and zero otherwise. We therefore can determine the boundary of the safe zone without using the equilibrium interest rate schedule in the crisis zone.

Computing the equilibrium is therefore straightforward: The crisis threshold $\boldsymbol{b}_{\lambda}$ is determined independently of $\boldsymbol{b}_{\pi}$ as explained in the previous paragraph. The crisis threshold is sufficient to determine the fiscal authority's policy function $C(b)$, described in (14). With $C(b)$ in hand, $\boldsymbol{b}_{\pi}$ is determined from (17). The final step is to verify that these thresholds indeed determine a monotone equilibrium. That is, for all $\boldsymbol{b} \leq \boldsymbol{b}_{\pi}$, the monetary authority's

\footnotetext{
${ }^{19}$ Note that this is very different than the fiscal externality in section 3.3. In that case, there was not a consistent set of equilibrium beliefs that resolved the fiscal externality. Indeed, this result stems from the fact that there is no fiscal externality in the grace period as the interest rate on debt in arrears is constant.
} 
best response is zero inflation, and similarly $\bar{\pi}$ is optimal for $\boldsymbol{b}>\boldsymbol{b}_{\pi}$.

Lemma 5 in Appendix B states the necessary conditions to ensure that the thresholds above constitute an equilibrium.

\subsection{Crisis Vulnerability and the Debt Distribution}

A major goal of our analysis is to understand how the composition of the monetary union affects the vulnerability to rollover crises. We do so by characterizing the dependence of $\boldsymbol{b}_{\lambda}$ on $\eta$. Figure 3 describes how the threshold $\boldsymbol{b}_{\lambda}$ varies with the fraction of debtors $\eta$. The vertical axis represents the candidate $\boldsymbol{b}_{\lambda}$ and the horizontal axis is the parameter $\eta$.

The downward sloping line labelled $\mathcal{R}$ is a reference line that defines when the indicator function in equation (21) is zero or one. Specifically, it traces the points such that $u^{\prime}(y-$ $\left.\rho \boldsymbol{b}_{\lambda}\right) \boldsymbol{b}_{\lambda}=\psi_{0} / \eta$. If $\boldsymbol{b}_{\lambda}$ lies strictly above this reference, then in equilibrium $r\left(\boldsymbol{b}_{\lambda}, \boldsymbol{b}_{\lambda}\right)=\rho+\bar{\pi}$. If $\boldsymbol{b}_{\lambda}$ lies weakly below this line, then $r\left(\boldsymbol{b}_{\lambda}, \boldsymbol{b}_{\lambda}\right)=\rho$. The line slopes down because as the fraction of debtors increases, the monetary authority will start inflating at lower thresholds.

Below the $\mathcal{R}$ locus, we obtain $\boldsymbol{b}_{\lambda}$ by substituting $\rho$ for $r$ in (20). As $\eta \rightarrow 0$, the debtors as a group are too small to affect monetary policy during a crisis. The monetary authority therefore provides no assistance. As $\eta$ increases, the monetary authority is willing to inflate in the off-equilibrium event that a crisis arrives in the safe zone. This expands the safe zone, and therefore the threshold $\boldsymbol{b}_{\lambda}$ increases. This is the segment $\overline{A B}$ depicted in the figure.

Above the $\mathcal{R}$ locus, we obtain $\boldsymbol{b}_{\lambda}$ by substituting $\rho+\bar{\pi}$ for $r$ in (20). As $V^{G}$ is strictly decreasing in $\tilde{r}$, this threshold is strictly below that when $\tilde{r}=\rho$, conditional on monetary policy. As $\eta$ increases, the safe zone is expanded as the monetary authority provides more support in the grace period, while $\tilde{r}$ does not change. This generates the upward sloping segment $\overline{C D}$.

At point $B$, the fiscal authority is indifferent to repayment versus default when $\tilde{r}=\rho$. At point $C$, the fiscal authority is indifferent when $\tilde{r}=\rho+\bar{\pi}$. There is an intermediate region when the fiscal authority strictly prefers repayment when $\tilde{r}=\rho$, but strictly prefers default when $\tilde{r}=\rho+\bar{\pi}$. As a result, the condition defining the threshold (20) traces the downward sloping locus $\mathcal{R}$ along the segment $\overline{B C}$. When $\boldsymbol{b}_{\lambda}$ lies on $\mathcal{R}$, then the crisis threshold $\boldsymbol{b}_{\lambda}$ and the equilibrium inflation threshold $\boldsymbol{b}_{\pi}$ are equivalent.

The threshold $\boldsymbol{b}_{\lambda}$ is therefore non-monotonic in the fraction of debtors $\eta$. This reflects the monetary authority's tension between the on-equilibrium temptation to inflate and the off-equilibrium promise to come to the aid in a crisis. At point $B$, we have the maximal safe zone as we vary the fraction of debtors in the monetary union. This is the closest approximation to a commitment not to inflate absent a crisis, but to optimally inflate in the 
event of a crisis. For $\eta$ below point $B$, the monetary authority can commit to low inflation absent a crisis, but not credibly promise to act aggressively in the event of a crisis.

Conversely, along the segment $\overline{B C}$, the threshold is determined by the debt level at which the monetary authority begins to inflate absent a crisis. This is because, for debt levels above $\mathcal{R}$, the monetary authority cannot credibly promise low inflation. Along the segment $\overline{B C}$, the equilibrium interest rate is $\rho$. At that nominal interest rate, the union could support more debt without becoming vulnerable to a crisis. However, it cannot support more debt at a higher nominal interest rate. This is because the increase in interest rate reduces the ability of the monetary authority to rescue debtors in a crisis. As a result, the threshold is determined in this region by the indifference condition of the monetary authority regarding equilibrium inflation.

The fact that the safe region is maximized at an interior $\eta$ is relevant for our discussion of optimal monetary union composition, which is contained in the next section. ${ }^{20}$

\section{Optimal Composition of a Currency Union}

In the case without self-fulfilling crises, a country with high debt is strictly better off when every other member has low debt $(\eta \rightarrow 0)$, as discussed in Section 3. This composition of the currency union endogenously lowers the benefit of inflation for the monetary authority thus enabling it to deliver the commitment outcome of zero inflation. However, this conclusion changes when countries are exposed to rollover risk. In this case a country with high debt may be better off when there is an appropriate measure of high debtors. This reflects the fact that the crisis region is minimized at an interior $\eta$ in Figure 3.

To illustrate this, consider Figure 4. Each panel depicts an equilibrium value for two different values of $\eta$. Case $A$ refers to $\eta=0$, which was point $A$ in Figure 3 . At point $A$, the set of debtors is measure zero, and so equilibrium inflation is always zero. Case $B$ refers to the $\eta$ at point $B$ in Figure 3, which minimizes the crisis region. Recall that at point $B$, in equilibrium $\boldsymbol{b}_{\lambda}=\boldsymbol{b}_{\pi}$. A superscript denotes the respective case.

The figure has three panels. Panel (a) depicts the representative fiscal authority's equi-

\footnotetext{
${ }^{20}$ In the model we do not allow for spillovers, say through a banking channel, on low debtors in the event of a default by high debtors. If there exist such spillover costs it is reasonable to assume that this cost is strictly increasing in the measure of defaulters. The presence of such costs does not alter any individual fiscal authority's decisions on consumption, borrowing or default. However, the monetary authority, which cares about the union as a whole, will be more tempted to intervene in the event of a run on high-debtors because of the spillover effect on low-debtors. This will quantitatively impact the debt threshold and increase the size of the safe zone relative to the case without spillovers. The non-monotonic relation between the debt threshold and the fraction of high debtors in the union is maintained, except that it shifts up relative to what is depicted in Figure 3.
} 
librium value function $V(\boldsymbol{b}, \boldsymbol{b})$ inclusive of inflation costs, where we impose symmetry. Panel (b) depicts the value net of inflation costs, $\hat{V}(\boldsymbol{b})$. Panel (c) depicts the inflation costs, $V-\hat{V}$.

We start with panel (b). For $\boldsymbol{b} \leq \boldsymbol{b}_{\lambda}^{A}, \hat{V}^{A}(\boldsymbol{b})=\hat{V}^{B}(\boldsymbol{b})=u(y-\rho \boldsymbol{b}) / \rho$. For $\boldsymbol{b} \in\left(\boldsymbol{b}^{A}, \boldsymbol{b}^{B}\right]$, equilibrium $A$ is vulnerable to a rollover crisis, while equilibrium $B$ is safe. This reflects the value of having the monetary authority stand ready to assist in the event of a crisis, which is only credible if there are a sufficient number of debtors. On this domain, $\hat{V}^{A}<\hat{V}^{B}$. Recall that in the neighborhood to the right of $\boldsymbol{b}_{\lambda}$, a fiscal authority will save. From the first order condition $u^{\prime}(C(\boldsymbol{b}))=-\hat{V}^{\prime}(\boldsymbol{b})$, this translates into a steeper slope for $\hat{V}^{A}$ than for $\hat{V}^{B}$.

For $\boldsymbol{b}>\boldsymbol{b}_{\lambda}^{B}$, both $A$ and $B$ are vulnerable to a rollover crisis. However, by continuity, $\hat{V}^{B}$ continues to lie above $\hat{V}^{A}$. This reflects that less saving is required to eliminate the threat of a crisis in case $B$. For $\boldsymbol{b} \geq b^{* B}$, debt is stationary in the crisis zone for both cases. Therefore, $\hat{V}^{A}=\hat{V}^{B}$ for $\boldsymbol{b} \geq b^{* B}$.

Turning to panel (c), we see that equilibrium $A$ benefits from the commitment to low inflation because it avoids inflation costs. For equilibrium $A$, inflation is always zero and therefore $V^{A}-\hat{V}^{A}=0$. Recall that for case $B, \boldsymbol{b}_{\lambda}^{B}=\boldsymbol{b}_{\pi}^{B}$. For $\boldsymbol{b} \leq \boldsymbol{b}_{\pi}, V^{B}=\hat{V}^{B}$ as there is no inflation in equilibrium. For $\boldsymbol{b}>\boldsymbol{b}_{\pi}^{B}, V^{B}<\hat{V}^{B}$, as inflation is strictly positive on this domain. However, the present value of inflation costs is relatively small in the neighborhood of $\boldsymbol{b}_{\pi}$ as the fiscal authority is saving towards $\boldsymbol{b}_{\pi}^{B}=\boldsymbol{b}_{\lambda}^{B}$. The further $\boldsymbol{b}$ is above $\boldsymbol{b}_{\pi}^{B}$, the greater the present value of costs. For $\boldsymbol{b} \geq b^{* B}$, the fiscal authority does not save, and $V^{B}-\hat{V}^{B}=-\psi_{0} \bar{\pi} /(\rho+\lambda)$.

Panel (a) sums these two figures. On the domain $\left(\boldsymbol{b}_{\lambda}^{A}, \boldsymbol{b}_{\lambda}^{B}\right)$ we have $V^{B}>V^{A}$, as both have zero inflation costs but $\hat{V}^{B}>\hat{V}^{A}$ due to the latter's vulnerability to a crisis. There is therefore a range of debt over which welfare is higher for a debtor in a monetary union with a strictly positive measure of other debtors, compared to the case with no other debtors $(\eta=0)$. This contrasts with the non-crisis benchmark equilibrium when $\eta=0$ was the optimal composition for the representative debtor. Note that for $\boldsymbol{b} \leq \boldsymbol{b}_{\pi}^{B}$, the non-debtors are not worse off in a union with debtors, because inflation only happens off equilibrium.

However, in panel (b) we see that $\hat{V}^{A}=\hat{V}^{B}$ for high enough $\boldsymbol{b}$, while panel (c) implies a strict welfare loss due to inflation in case $B$. This implies that $V^{A}>V^{B}$ for high $\boldsymbol{b}$, which is depicted in panel (a) to the right of the intersection.

\section{Conclusion}

The ongoing eurozone crisis has brought to the forefront the inherent tensions in a monetary union where individual countries have control over fiscal decisions but where monetary decisions are made by a union wide monetary authority that maximizes welfare of the union as a 
whole. It is a familiar argument that individual countries in a union are worse off when there is limited synchronization in business cycles across countries, as a common monetary policy for the union can be inconsistent with the needs of different countries. Here we highlight another tension that arises when countries are subject to rollover risk in debt markets.

The monetary authority may be able to use surprise inflation to reduce the real value of debt owed and thus eliminate a rollover crisis. Whether it will choose to do so and whether it can effectively do so depends on the aggregate level of debt in the union. If the aggregate level of debt in the union is low, the monetary authority will choose never to inflate, neither in tranquil nor in crisis time. At the other extreme, if the aggregate debt in the union is high, the monetary authority uses inflation all the time and consequently fails to generate surprise inflation. On the other hand when there is an intermediate level of aggregate debt the monetary authority chooses low inflation in normal times and high inflation in crisis times, thus generating surprise inflation and helping to prevent a rollover crisis. An indebted country in the union therefore gets no help from the monetary authority in preventing self-fulfilling crises when everyone else in the union is as indebted as it is or when no one in the union is like it. Greece is better off in a monetary union with members like Germany, but not exclusively low debtors. The presence of other vulnerable debtors, like Italy, Spain, Ireland, and Portugal, makes the ECB promised intervention in a crisis credible. This composition gives debtors both low inflation and eliminates its exposure to self-fulfilling crises. Importantly, this can take place without any loss of welfare to non-debtors if the use of inflation is done off-equilibrium. ${ }^{21}$

What this analysis also highlights is that there is an intermediate range of debt at which Greece may be better off with independent monetary policy than being a part of a monetary union with only low debtors. This is because with independent monetary policy it is credibly able to commit to the use of inflation in the event of a run on its debt and thereby can eliminate a rollover crisis. If, however, Greek debt is high, it would be better off in a monetary union with low debtors because it can benefit from the low inflation the union is credibly able to offer without any loss in terms of exposure to rollover risk. This follows because with high debt independent monetary policy results in high inflation in normal times and therefore cannot generate surprise inflation in crisis times.

While we do not capture important aspects of the eurozone crisis, particularly the role of the banking sector in amplifying the crisis, our analysis is consistent with the events following the so-called Draghi put in the summer of 2012, when Draghi promised to do "whatever it

\footnotetext{
${ }^{21}$ We have described an environment where the debt of members of the union is held outside the union. In reality, as in the case of the eurozone, a significant fraction of the debt is held by members of the union. In our environment this would have similar effects to reducing $\eta$ and therefore the incentive to inflate.
} 
takes" to save the euro. This intervention caused spreads of troubled periphery country bonds to decline sharply despite the absence of any actual purchase by the ECB of such bonds (and importantly differs from the subsequent 2015 monetary accommodation in the form of a Quantitative Easing program involving euro area sovereign bonds).

Clearly, debt crises disappear when a country's debt is low enough. However, we demonstrate the existence of a fiscal externality that limits individual countries' incentive to reduce their debt. This arises because they fail to internalize the impact of their debt on the union monetary authority's incentive to inflate. Consequently they end up with higher debt than if they were an independent country with control over both fiscal and monetary policy. This provides an argument for placing debt ceilings on countries in a monetary union. 


\section{A Fiscal and Default Externalities in Rollover Crises}

In this appendix, we show that the coordinated fiscal-monetary response during the grace period can be decentralized in our monetary union equilibrium in which the policies are set by independent authorities. We first state the grace period problem for a single decision maker:

$$
V_{E}^{G}(\boldsymbol{b}, \tilde{r})=\max _{\{\pi(t) \in[0, \bar{\pi}], c(t)\}} \int_{0}^{\delta} e^{-\rho t}\left(\eta u(c(t))+(1-\eta) u(y)-\psi_{0} \pi(t)\right) d t+e^{-\rho \delta} \frac{u(y)}{\rho}
$$

subject to

$$
\begin{aligned}
\dot{\boldsymbol{b}}(t) & =c(t)+(\tilde{r}-\pi(t)) \boldsymbol{b}(t)-y, \\
\dot{\boldsymbol{b}}(t) \leq-\pi(t) \boldsymbol{b}(t) & \leq \boldsymbol{b}(0)=\boldsymbol{b}, \quad \boldsymbol{b}(\delta)=0
\end{aligned}
$$

where as before $\tilde{r}$ is the contracted interest rate at the start of the crisis (which is the equilibrium rate of the decentralized monetary union). For this problem, consumption and inflation are coordinated.

Let $\pi_{E}(t)$ be the optimal inflation policy from this problem. Now consider an individual fiscal authority's problem conditional on $\pi_{E}$. This problem net of inflation costs is:

$$
\hat{V}^{G}\left(b, \tilde{r} ; \pi_{E}\right)=\max _{\{c(t)\}} \int_{0}^{\delta} e^{-\rho t} u\left(c(t) d t+e^{-\rho \delta} \frac{u(y)}{\rho},\right.
$$

subject to

$$
\begin{aligned}
& \dot{b}(t)=c(t)+\left(\tilde{r}-\pi_{E}(t)\right) b(t)-y, \\
& \dot{b}(t) \leq-\pi_{E}(t) b(t), \\
& b(0)=b, \quad b(\delta)=0 .
\end{aligned}
$$

It is clear that the optimal individual fiscal policy coincides with that from Problem (22). That is, the unitary fiscal policy is the best response to $\pi_{E}$ in the monetary union equilibrium. Similarly, $\pi_{E}$ is the monetary authority's best response to this fiscal policy. Therefore, the single-decision-maker policies can be sustained in the monetary union equilibrium.

This implies that there is no fiscal externality in the grace period problem. The key difference between this problem and the equilibrium fiscal policy problem is that the interest rate for the grace period is a constant; in particular, it is not a function of fiscal decisions. 
Outside of the grace period (on the equilibrium path), fiscal authorities fail to internalize the impact their individual debt choices have on the aggregate debt, and therefore have on $r(b, \boldsymbol{b})$.

Despite the absence of the traditional fiscal externality in the grace period, there remains a "default externality." The default externality arises because there may be more than one equilibrium best response from the monetary union. If the fiscal authorities default, the monetary authority will not inflate thus making repayment difficult. Conversely, an alternative equilibrium response may exist in which fiscal authorities repay within the grace period, aided by accommodative monetary policy.

While the default externality may be of interest in some contexts, it is not robust to a straightforward coordination of beliefs among members of the monetary union. In particular, since the solution to Problem (22) can be supported in the decentralized equilibrium, it is reasonable that the monetary authority can coordinate beliefs on this outcome. That is, if fiscal authorities believe that the monetary authority will help them during the grace period by setting $\pi=\pi_{E}$, they will only default if $\hat{V}^{G}<\underline{\hat{V}}$, where $\hat{V}^{G}$ solves Problem (23). Note that this is the same default criterion that would be used by a unified decision maker.

\section{B Existence and Characterization of Monotone Equi- libria}

In this appendix, we characterize the monetary authority's equilibrium value function and associated inflation policy. We first consider an arbitrary monotone threshold equilibrium and characterize the value function of the monetary authority that is implied by creditor beliefs. That is, consider an equilibrium interest rate function $r(b, \boldsymbol{b})$ defined by the crisis threshold $\boldsymbol{b}_{\lambda}$ defined by (20), an arbitrary inflation threshold $\tilde{b}_{\pi}$, and a domain $\bar{\Omega}=\left[0, b_{\max }\right]$ that sets an upper bound on debt. The associated equilibrium beliefs are therefore $\Pi(\boldsymbol{b})=0$ for $\boldsymbol{b} \leq \tilde{b}_{\pi}$ and $\bar{\pi}$ otherwise. Lemma 3 derives the value function implied by this policy. Lemma 4 establishes that $\boldsymbol{b}_{\pi}$ defined in equation (17) is an upper bound on the set of possible equilibrium inflation thresholds. Finally, Lemma 5 establishes that the monetary authority has no incentive to deviate from the policy implied by the threshold $\boldsymbol{b}_{\pi}$. These lemmas constitute the proof of Proposition 2 that states $\boldsymbol{b}_{\pi}$ is the threshold associated with the best monotone equilibrium.

We establish these points assuming the borrowing limit $b_{\max }$ lies above the thresholds $\boldsymbol{b}_{\pi}, \boldsymbol{b}_{\lambda}$ and $b^{*}$. This is without loss of generality in terms of establishing optimal monetary policy as the location of the borrowing limit relative to these thresholds does not influence 
the monetary authority's problem on the interior of $\bar{\Omega}$. It is straightforward to then truncate the monetary authority's value and policy functions to the appropriate domain $\bar{\Omega}=\left[0, b_{\max }\right]$.

The next lemma characterizes the monetary authority's value function conditional on the triplet $\left\{\boldsymbol{b}_{\lambda}, \tilde{b}_{\pi}, b_{\max }\right\}$. We discuss the key characteristics of the value function after the proof of the lemma. For reference, recall that associated with any equilibrium is a consumption policy function $C(b)$ defined in (14) and characterized by $c_{\lambda}$ from (13) and the associated $b^{*}=\left(y-c_{\lambda}\right) /(\rho+\lambda)$.

Lemma 3. In any monotone equilibrium with thresholds $\left\{\boldsymbol{b}_{\lambda}, \tilde{b}_{\pi}\right\}$ and domain $\bar{\Omega}=\left[0, b_{\max }\right]$, the monetary authority's value function $J$ satisfies

$$
J(\boldsymbol{b})=\eta \hat{V}(\boldsymbol{b})+(1-\eta) \frac{u(y)}{\rho}-\Psi(\boldsymbol{b}),
$$

where $\hat{V}$ is defined by (12) and $\Psi(\boldsymbol{b})$ is:

(i) If $\tilde{b}_{\pi}<\boldsymbol{b}_{\lambda}$, then:

$$
\Psi(\boldsymbol{b})=\left\{\begin{array}{l}
0 \text { if } \boldsymbol{b} \leq \tilde{b}_{\pi} \\
\frac{\psi_{0} \bar{\pi}}{\rho} \text { if } \tilde{b}_{\pi}<\boldsymbol{b} \leq \boldsymbol{b}_{\lambda} \\
\frac{\psi_{0} \bar{\pi}\left((\rho+\lambda) b^{*}-\rho \boldsymbol{b}_{\lambda}-\lambda \boldsymbol{b}\right)}{\rho(\rho+\lambda)\left(b^{*}-\boldsymbol{b}_{\lambda}\right)} \text { if } \boldsymbol{b}_{\lambda}<\boldsymbol{b} \leq b^{*} \\
\frac{\psi_{0} \bar{\pi}}{\rho+\lambda} \text { if } b^{*}<\boldsymbol{b}
\end{array}\right.
$$

(ii) If $\boldsymbol{b}_{\lambda} \leq \tilde{b}_{\pi}$, then:

$$
\Psi(\boldsymbol{b})=\left\{\begin{array}{l}
0 \text { if } \boldsymbol{b} \leq \tilde{b}_{\pi} \\
\frac{\psi_{0} \bar{\pi}\left(\boldsymbol{b}-\tilde{b}_{\pi}\right)}{(\rho+\lambda)\left(b^{*}-\tilde{b}_{\pi}\right)} \text { if } \tilde{b}_{\pi}<\boldsymbol{b} \leq b^{*} \\
\frac{\psi_{0} \bar{\pi}}{\rho+\lambda} \text { if } \max \left\{\tilde{b}_{\pi}, b^{*}\right\}<\boldsymbol{b} .
\end{array}\right.
$$

Proof. $\Psi(\boldsymbol{b})$ denotes the present discounted cost of inflation in the authority's problem (P5) starting from initial debt $\boldsymbol{b}$ and evaluated at the equilibrium policy functions:

$$
\Psi(\boldsymbol{b})=\psi_{0} \bar{\pi} \int_{0}^{\infty} e^{-\rho t-\lambda \int_{0}^{t} \mathbb{I}_{\mathbb{C}}(\boldsymbol{b}(s)) d s} \mathbb{I}\left\{\boldsymbol{b}(t)>\tilde{b}_{\pi}\right\}
$$

where $\mathbb{I}\left\{\boldsymbol{b}(t)>\tilde{b}_{\pi}\right\}$ is an indicator that debt is in the inflation zone at $t$, and $\boldsymbol{b}(t)$ follows the equilibrium law of motion for debt conditional on $\boldsymbol{b}(0)=\boldsymbol{b}$.

We can evaluate $\Psi(\boldsymbol{b})$ by denoting the equilibrium time until exit from the high-inflation 
and crisis zones, respectively, starting from $\boldsymbol{b}$ :

$$
\begin{aligned}
& T_{\pi}(\boldsymbol{b}) \equiv \inf \left\{t \mid \boldsymbol{b}(t) \leq \tilde{b}_{\pi}\right\} \\
& T_{\lambda}(\boldsymbol{b}) \equiv \inf \left\{t \mid \boldsymbol{b}(t) \leq \boldsymbol{b}_{\lambda}\right\}
\end{aligned}
$$

where the dynamics start from $\boldsymbol{b}(0)=\boldsymbol{b}$. Let $T=\min \left\{T_{\pi}, T_{\lambda}\right\}$. Using the debt dynamics from equation (15), we have:

$$
e^{-(\rho+\lambda) T_{\lambda}(\boldsymbol{b})}=\left\{\begin{array}{l}
1 \text { if } \boldsymbol{b} \leq \boldsymbol{b}_{\lambda} \\
\frac{b^{*}-\boldsymbol{b}}{b^{*}-\boldsymbol{b}_{\lambda}} \text { if } \boldsymbol{b}_{\lambda}<\boldsymbol{b} \leq b^{*} \\
0 \text { if } b^{*}<\boldsymbol{b}
\end{array}\right.
$$

and

$$
e^{-(\rho+\lambda) T_{\pi}(\boldsymbol{b})}=\left\{\begin{array}{l}
1 \text { if } \boldsymbol{b} \leq \tilde{b}_{\pi} \\
\frac{b^{*}-\boldsymbol{b}}{b^{*}-\tilde{b}_{\pi}} \text { if } \boldsymbol{b}_{\lambda} \leq \tilde{b}_{\pi}<\boldsymbol{b} \leq b^{*} \\
0 \text { otherwise }
\end{array}\right.
$$

With these definitions, we can write:

$$
\begin{aligned}
\Psi(\boldsymbol{b}) & =\psi_{0} \bar{\pi}\left\{\int_{0}^{T(\boldsymbol{b})} e^{-(\rho+\lambda) t} d t+\mathbb{I}_{\left\{T_{\pi}(\boldsymbol{b})>T_{\lambda}(\boldsymbol{b})\right\}} \int_{T_{\lambda}(\boldsymbol{b})}^{T_{\pi}(\boldsymbol{b})} e^{-\rho t} d t\right\} \\
& =\psi_{0} \bar{\pi}\left\{\frac{1-e^{-(\rho+\lambda) T(\boldsymbol{b})}}{\rho+\lambda}+\frac{\mathbb{I}_{\left\{T_{\pi}(\boldsymbol{b})>T_{\lambda}(\boldsymbol{b})\right\}} e^{-\rho T_{\lambda}(\boldsymbol{b})}}{\rho}\right\},
\end{aligned}
$$

where the second line uses the fact that $T_{\pi}(\boldsymbol{b})=\infty$ if $T_{\pi}(\boldsymbol{b})>T_{\lambda}(\boldsymbol{b})$.

Substituting in, if $\tilde{b}_{\pi}<\boldsymbol{b}_{\lambda}$, then:

$$
\Psi(\boldsymbol{b})=\left\{\begin{array}{l}
0 \text { if } \boldsymbol{b} \leq \tilde{b}_{\pi} \\
\frac{\psi_{0} \bar{\pi}}{\rho} \text { if } \tilde{b}_{\pi}<\boldsymbol{b} \leq \boldsymbol{b}_{\lambda} \\
\frac{\psi_{0} \bar{\pi}\left((\rho+\lambda) b^{*}-\rho \boldsymbol{b}_{\lambda}-\lambda \boldsymbol{b}\right)}{\rho(\rho+\lambda)\left(b^{*}-\boldsymbol{b}_{\lambda}\right)} \text { if } \boldsymbol{b}_{\lambda}<\boldsymbol{b} \leq b^{*} \\
\frac{\psi_{0} \bar{\pi}}{\rho+\lambda} \text { if } b^{*}<\boldsymbol{b} ;
\end{array}\right.
$$


and if $\boldsymbol{b}_{\lambda} \leq \tilde{b}_{\pi}$, then:

$$
\Psi(\boldsymbol{b})=\left\{\begin{array}{l}
0 \text { if } \boldsymbol{b} \leq \tilde{b}_{\pi} \\
\frac{\psi_{0} \bar{\pi}\left(\boldsymbol{b}-\tilde{b}_{\pi}\right)}{(\rho+\lambda)\left(b^{*}-\tilde{b}_{\pi}\right)} \text { if } \tilde{b}_{\pi}<\boldsymbol{b} \leq b^{*} \\
\frac{\psi_{0} \bar{\pi}}{\rho+\lambda} \text { if } \max \left\{\tilde{b}_{\pi}, b^{*}\right\}<\boldsymbol{b}
\end{array}\right.
$$

The monetary authority's value inherits the values net of inflation for the member countries, specifically $\hat{V}$ for debtors and $u(y) / \rho$ for non-debtors. The term $\Psi(\boldsymbol{b})$ defined in $(25)$ and (26) denotes the present value of inflation costs.

In both cases, if $\boldsymbol{b} \leq \tilde{b}_{\pi}$, debt is below the inflation threshold and the monetary authority never inflates. Therefore $\Psi(\boldsymbol{b})=0$ of $\boldsymbol{b} \leq \tilde{b}_{\pi}$.

For $\boldsymbol{b}>b^{*}$, then the fiscal authority never saves. If $b^{*}>\tilde{b}_{\pi}$, this implies that $\Psi(\boldsymbol{b})=$ $\psi_{0} \bar{\pi} /(\rho+\lambda)$, which is the present value of $\psi_{0} \bar{\pi}$, with a discount rate of $\rho+\lambda$. The presence of $\lambda$ in the discount rate reflects that after default, inflation is zero.

Recall that the fiscal authority only saves due to crisis risk, not inflation risk. Therefore, if $\boldsymbol{b} \in\left(\tilde{b}_{\pi}, \boldsymbol{b}_{\lambda}\right]$, then the fiscal authority does not save. This is the fiscal externality. The present value of inflation costs in this region therefore equals $\psi_{0} \bar{\pi} / \rho$. This is only relevant if $\tilde{b}_{\pi}<\boldsymbol{b}_{\lambda}$, which is the first case in the proposition.

If $\boldsymbol{b} \in\left(\boldsymbol{b}_{\lambda}, b^{*}\right)$, then the fiscal authority will reduce its debt in equilibrium. If $\boldsymbol{b}_{\lambda}<\tilde{b}_{\pi}$, this is sufficient to eventually eliminate inflation. This is the middle term of equation (26), and represents the integral of inflation costs from $t=0$ until the time $\boldsymbol{b}(t)=\tilde{b}_{\pi}$.

However, if $\tilde{b}_{\pi}<\boldsymbol{b}_{\lambda}$, then the fiscal authority stops reducing debt before reaching the inflation threshold. This poses a challenge to the monetary authority. On the one hand, it values the reduction in default probability, which is captured by $\hat{V}$. On the other hand, inflation will never be zero absent default. Therefore, there is a silver lining to the default cloud. Inspection of the third term in (25) reveals that $\Psi^{\prime}(\boldsymbol{b})<0$ for $\boldsymbol{b} \in\left(\boldsymbol{b}_{\lambda}, b^{*}\right)$. That is, inflation costs are decreasing in the level of debt. This raises the question of whether the monetary authority will set inflation to zero in an attempt to delay exit from the crisis region. This may happen if default costs are low and/or inflation costs are very high. This may break the monotonicity of any equilibrium inflation policy. We view this as a pathological outcome, but without restrictions on parameters we cannot rule it out a priori. As a result, we impose the following condition: 
Assumption 1 (Monotonicity). If $\boldsymbol{b}_{\pi}<\boldsymbol{b}_{\lambda}$ and if $\boldsymbol{b}_{\lambda}$ is in the interior of $\bar{\Omega}$ then:

$$
\eta u^{\prime}\left(c_{\lambda}\right) \boldsymbol{b}_{\lambda}-\psi_{0}\left(1+\frac{\lambda \bar{\pi} \boldsymbol{b}_{\lambda}}{\rho(\rho+\lambda)\left(b^{*}-\boldsymbol{b}_{\lambda}\right)}\right) \geq 0
$$

where $c_{\lambda}$ is defined by (13) and $b^{*}=y-(\rho+\lambda) c_{\lambda}$.

Note that this condition is stated in terms of equilibrium variables. However, equations (17) and (20) uniquely pin down these thresholds conditional on parameters.

We now establish that $\boldsymbol{b}_{\pi}$ is an upper bound on equilibrium inflation thresholds:

Lemma 4. The inflation threshold $\boldsymbol{b}_{\pi}$ defined in equation (17) is an upper bound inflation threshold. That is, if $\tilde{b}_{\pi}$ is an equilibrium threshold such that $\Pi(\boldsymbol{b})=0$ for $\boldsymbol{b} \leq \tilde{b}_{\pi}$ and $\Pi(\boldsymbol{b})=\bar{\pi}$ for $\boldsymbol{b} \in\left(\tilde{b}_{\pi}, b_{\max }\right]$, then $\tilde{b}_{\pi} \leq \boldsymbol{b}_{\pi}$.

Proof. To generate a contradiction, suppose otherwise. Specifically, suppose $\tilde{b}_{\pi}>\boldsymbol{b}_{\pi}$, and consider $\boldsymbol{b} \in\left(\boldsymbol{b}_{\pi}, \tilde{b}_{\pi}\right)$. For $\tilde{b}_{\pi}$ to be consistent with equilibrium, we require that zero inflation is optimal at $\boldsymbol{b}<\tilde{b}_{\pi}$. By inspecting the characterization of the value functions for the monetary authority obtained in Lemma 3, we note that $J^{\prime}(\boldsymbol{b})=\eta \hat{V}^{\prime}(\boldsymbol{b})=-\eta u^{\prime}(C(\boldsymbol{b}))$ for $\boldsymbol{b}<\tilde{b}_{\pi}$. As $\boldsymbol{b}>\boldsymbol{b}_{\pi}$, equation (17) implies we have $-J^{\prime}(\boldsymbol{b}) \boldsymbol{b}=\eta u^{\prime}(C(\boldsymbol{b})) \boldsymbol{b}>\psi_{0}$. From the monetary authority's first order condition, the optimal inflation is therefore $\bar{\pi}$, contradicting that $\tilde{b}_{\pi}$ is an equilibrium inflation threshold.

The next lemma verifies that $\boldsymbol{b}_{\pi}$ is indeed an equilibrium threshold. That is, faced with an interest rate defined by $\left\{\boldsymbol{b}_{\lambda}, \boldsymbol{b}_{\pi}, b_{\max }\right\}$, the monetary authority's best response is zero inflation for $\boldsymbol{b} \leq \boldsymbol{b}_{\pi}$ and $\pi=\bar{\pi}$ otherwise.

Lemma 5. If Assumption 1 holds, then the inflation threshold $\boldsymbol{b}_{\pi}$ and the crisis threshold $\boldsymbol{b}_{\lambda}$ characterizes a monotone equilibrium.

Proof. The premise is that creditors believe the monetary authority's policy is

$$
\Pi(\boldsymbol{b})=\left\{\begin{array}{l}
0 \text { if } \boldsymbol{b} \leq \boldsymbol{b}_{\pi} \\
\bar{\pi} \text { if } \boldsymbol{b}>\boldsymbol{b}_{\pi}
\end{array}\right.
$$

and the equilibrium interest rate is therefore $r(b, \boldsymbol{b})=\rho+\Pi(\boldsymbol{b})+\lambda \mathbb{I}_{\mathbb{C}}(b)$. The lemma states that $\Pi$ is the monetary authority's best response to $r$ and the fiscal authority's policy $C$ (which is independent of inflation).

We establish this as follows. We use the result of Bressan and Hong (2007) (henceforth, $\mathrm{BH}$ ) that the monetary authority's value function $J$ is the unique bounded continuous 
solution to the Hamilton-Jacobi-Bellman (HJB) equation (16) in the viscosity sense. The viscosity solution is a generalized solution concept to the differential equation that accommodates points of non-differentiability. See Section 3.1 of $\mathrm{BH}$ for a formal definition of a viscosity solution, as well as Aguiar et al. (2012) Definition 3. We then verify that the $J$ from Lemma 3 is a solution to the HJB and therefore is the monetary authority's value function. To apply BH, we consider three cases.

Case 1: $\boldsymbol{b}_{\pi}<\boldsymbol{b}_{\lambda}$

To characterize the monetary authority's problem, we exploit the fact that it has limited control over the state variable. Specifically, for $\boldsymbol{b} \in\left[0, \boldsymbol{b}_{\pi}\right]$, we have $r(\boldsymbol{b}, \boldsymbol{b})=\rho$ and $C(\boldsymbol{b})=$ $y-\rho \boldsymbol{b}$. Thus, feasible dynamics for $\pi \in[0, \bar{\pi}]$ are:

$$
\begin{aligned}
\dot{\boldsymbol{b}} & =C(\boldsymbol{b})+(\rho-\pi) \boldsymbol{b}-y \\
& =-\pi \boldsymbol{b} \leq 0
\end{aligned}
$$

Thus, $\left[0, \boldsymbol{b}_{\pi}\right]$ is an absorbing region for the monetary authority and we can consider the monetary authority's problem on this domain in isolation. From Lemma 3 case (i), it is straightforward to check that $J$ is the unique bounded classical solution to the HJB on $\left[0, \boldsymbol{b}_{\pi}\right]$. Moreover, $-J^{\prime}(\boldsymbol{b}) \boldsymbol{b}=\eta u^{\prime}(y-\rho \boldsymbol{b}) \boldsymbol{b} \leq \psi_{0}$ on this domain, validating $\Pi$ as the monetary authority's policy function.

The region $\left(\boldsymbol{b}_{\pi}, b_{\max }\right]$ is also absorbing for the monetary authority. To see this, note that $C(b)=y-\rho b$ for $b \leq \boldsymbol{b}_{\lambda}$, and $r(\boldsymbol{b}, \boldsymbol{b}) \geq \rho+\bar{\pi}$. Therefore, $\pi \leq \bar{\pi}$ implies that $\boldsymbol{b} \geq 0$ on the domain $\left(\boldsymbol{b}_{\pi}, \boldsymbol{b}_{\lambda}\right]$. It is not feasible for the monetary authority to exit the domain $\left(\boldsymbol{b}_{\pi}, b_{\max }\right]$. (This is why the value function is discontinuous at $\boldsymbol{b}_{\pi}$.) The candidate value function from Lemma 3 case (i) is continuous, but non-differentiable at $\boldsymbol{b}_{\lambda}$ and $b^{*}$. However, it satisfies the HJB in the viscosity sense, and the results of $\mathrm{BH}$ imply that the viscosity solution is the value function, and $\Pi$ is the associated policy function. The fact that $\Pi$ is the optimal policy relies on Assumption 1.

Case 2: $\boldsymbol{b}_{\lambda} \leq \boldsymbol{b}_{\pi}<b^{*}$

In this case, the candidate value function is case (ii) from Lemma 3, which is continuous over the entire domain $\bar{\Omega}$. The environment of $\mathrm{BH}$ requires that $\dot{\boldsymbol{b}}=0$ is feasible at points of discontinuity in $r$ and $C$; in particular, that $\boldsymbol{b}$ is feasible at $\boldsymbol{b}_{\pi}$ and $\boldsymbol{b}_{\lambda}$. The latter point presents no challenge as $\pi=0$ generates stationary debt at $\boldsymbol{b}_{\lambda}$ when $\boldsymbol{b}_{\lambda} \leq \boldsymbol{b}_{\pi}$. However, the fiscal authority is saving on the equilibrium path at $\boldsymbol{b}_{\pi}$ if $\boldsymbol{b}_{\pi} \in\left(\boldsymbol{b}_{\lambda}, b^{*}\right)$, and the monetary authority would need to set $\pi<0$ to generate (off equilibrium) a stationary level of debt. To 
accommodate this technicality, we relax the monetary authority's problem by expanding the choice set for inflation to $\underline{\pi}<0$, with a large but finite associated cost $\underline{\psi}$. That is, inflation costs are $\psi_{0} \pi$ if $\pi \in[0, \bar{\pi}]$ and $-\underline{\psi} \pi$ for $\pi \in[\underline{\pi}, 0]$. (Note that the true model is recovered when $\underline{\psi} \rightarrow \infty$.) We assume $\underline{\pi}$ satisfies $c_{\lambda}+(\rho+\lambda-\underline{\pi}) \boldsymbol{b}_{\pi}-y=0$ so that $\dot{\boldsymbol{b}}=0$ is feasible. We also assume that $\underline{\psi}$ is large enough that $\dot{\boldsymbol{b}}=0$ is never optimal for the monetary authority. By relaxing the problem off equilibrium, we now satisfy the technical conditions of $\mathrm{BH}$, which establishes that the value function is the unique continuous bounded viscosity solution to equation (16). It is straightforward to check that $J$ defined in case (ii) of Lemma 3 satisfies the HJB at points of differentiability. At the points of non-differentiability, $\left\{\boldsymbol{b}_{\lambda}, \boldsymbol{b}_{\pi}, b^{*}\right\}$, the value function satisfies the conditions from Section 3.1 of BH. Moreover, this value is achieved via the policy function $\Pi$.

\section{Case 3: $b^{*} \leq \boldsymbol{b}_{\pi}$}

This case is similar to Case 1 in that the domain can be segmented. The monetary authority cannot exit the regions $\left[0, \boldsymbol{b}_{\pi}\right]$ and $\left[\boldsymbol{b}_{\pi}, b_{\max }\right]$. The results of $\mathrm{BH}$ can be applied on each domain separately. On the latter domain, $J$ is a classical solution to the HJB. On the former region, $J$ is a continuous viscosity solution. On each domain, $\Pi$ is the associated policy function.

\section{Proof of Proposition 2}

Proof. Lemma 4 establishes that any threshold from a monotone equilibrium is bounded above by $\boldsymbol{b}_{\pi}$. Lemma 5 establishes that $\boldsymbol{b}_{\pi}$ is itself an equilibrium threshold. Therefore, it characterizes the best monotone equilibrium. 


\section{References}

Aguiar, M. and Amador, M. (2014). Sovereign Debt. In Gopinath, G., Helpman, E., and Rogoff, K., editors, Handbook of International Economics Volume 4. Elsevier.

Aguiar, M., Amador, M., Farhi, E., and Gopinath, G. (2012). Crisis and Commitment: Inflation Credibility and the Vulnerability to Self-fulfilling Debt Crises. Working paper.

Alesina, A. and Barro, R. J. (2002). Currency Unions. Quarterly Journal of Economics, $117(2): 409-436$.

Araujo, A., Leon, M., and Santos, R. (2012). Welfare Analysis of Currency Regimes with Defaultable Debts. Journal of International Economics.

Barro, R. J. and Gordon, D. B. (1983). Rules, discretion and reputation in a model of monetary policy. Journal of Monetary Economics, 12(1):101-121.

Beetsma, R. and Jensen, H. (2005). Monetary and fiscal policy interactions in a microfounded model of a monetary union. Journal of International Economics, 67(2):320-352.

Beetsma, R. and Uhlig, H. (1999). An Analysis of the Stability and Growth Pact. Economic Journal, 109(458):546-571.

Bressan, A. and Hong, Y. (2007). Optimal Control Problems on Stratified Domains. Networks and Heterogeneous Media, 2:313-331.

Chari, V. V. and Kehoe, P. J. (2007). On the need for fiscal constraints in a monetary union. Journal of Monetary Economics, 54(8):2399-2408.

Chari, V. V. and Kehoe, P. J. (2008). Time Inconsistency and Free-Riding in a Monetary Union. Journal of Money, Credit and Banking, 40(7):1329-1356.

Cole, H. and Kehoe, T. (2000). Self-Fulfilling Debt Crises. Review of Economic Studies, 67:91-116.

Cooper, R., Kempf, H., and Peled, D. (2010). Regional debt in monetary unions: Is it inflationary? European Economic Review, 54(3):345-358.

Cooper, R., Kempf, H., and Peled, D. (2014). Insulation Impossible: Fiscal Spillovers in a Monetary Union. Journal of the European Economic Association, 12(2):465-491.

De Grauwe, P. (2011). The European Central Bank: Lender of Last Resort in the Government Bond Markets? CESifo Working Paper Series 3569, CESifo Group Munich. 
Dixit, A. and Lambertini, L. (2001). Monetary-fiscal policy interactions and commitment versus discretion in a monetary union. European Economic Review, 45(4-6):977-987.

Dixit, A. and Lambertini, L. (2003). Symbiosis of monetary and fiscal policies in a monetary union. Journal of International Economics, 60(2):235-247.

Farhi, E. and Werning, I. (2013). Fiscal Unions. Working paper.

Ferrero, A. (2009). Fiscal and monetary rules for a currency union. Journal of International Economics, 77(1):1-10.

Gali, J. and Monacelli, T. (2008). Optimal monetary and fiscal policy in a currency union. Journal of International Economics, 76(1):116-132.

Lopez, C. and Papell, D. H. (2012). Convergence of Euro area inflation rates. Journal of International Money and Finance, 31(6):1440-1458.

Mundell, R. (1961). A Theory of Optimum Currency Areas. American Economic Review, 51:657-665.

Rogers, J. H. (2001). Price level convergence, relative prices, and inflation in Europe. International Finance Discussion Papers 699, Board of Governors of the Federal Reserve System (U.S.).

Rogoff, K. (1985a). Can International Monetary Cooperation be Counterproductive? Journal of International Economics, 18:199-217.

Rogoff, K. (1985b). The Optimal Degree of Commitment to an Intermediate Monetary Target. Quarterly Journal of Economics, 100(4):1169-89.

Silva, J. S. and Tenreyro, S. (2010). Currency Unions in Prospect and Retrospect. Annual Review of Economics, 2(1):51-74.

Velasco, A. (2000). Debts and deficits with fragmented fiscal policymaking. Journal of Public Economics, 76(1):105-125.

Von Hagen, J. and Eichengreen, B. (1996). Federalism, Fiscal Restraints, and European Monetary Union. American Economic Review, 86(2):134-38. 


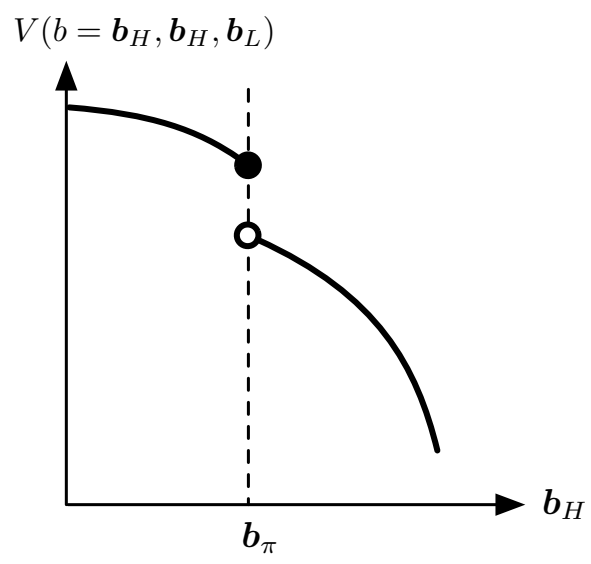

(a) Value Function

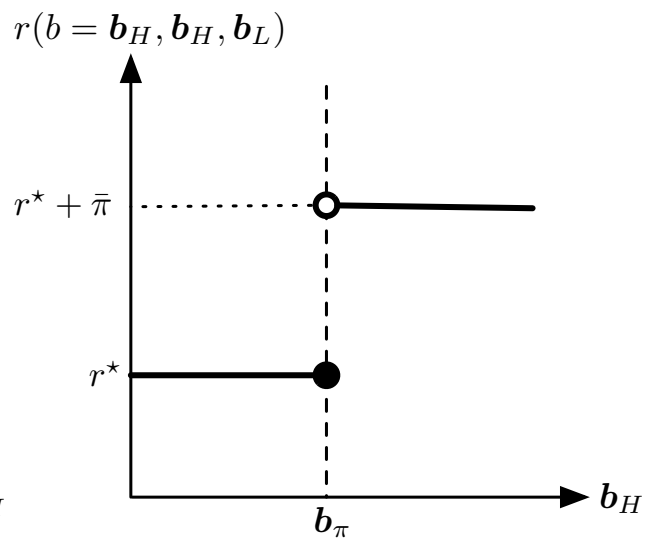

(b) Interest Rates

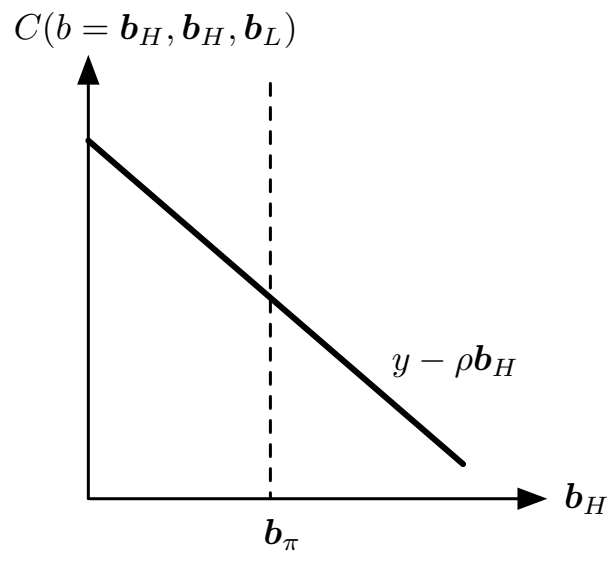

(c) Consumption Policy

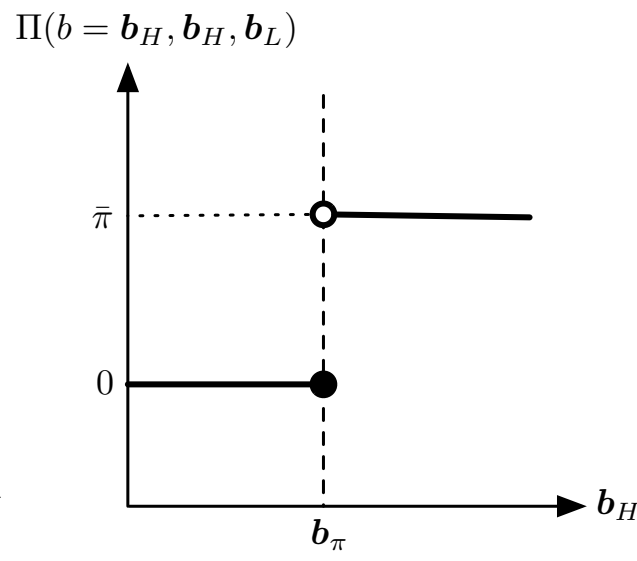

(d) Inflation Policy

Figure 1: Equilibrium in the Monetary Union with No Crisis

This figure depicts the equilibrium fiscal value function, interest rate schedule, consumption function, and inflation policy function. Specifically, the value function is depicted as a function of $b$, imposing the equilibrium symmetry condition $b=\boldsymbol{b}_{H}$. The discontinuity indicates the level of aggregate debt at which inflation jumps from zero to $\bar{\pi}$ (bottom right). The consumption function is also depicted imposing that idiosyncratic debt equals $\boldsymbol{b}_{H}$. 


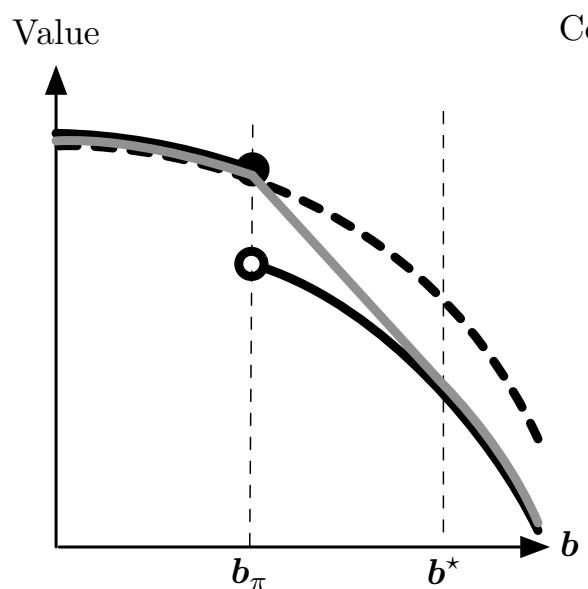

(a) Value Functions

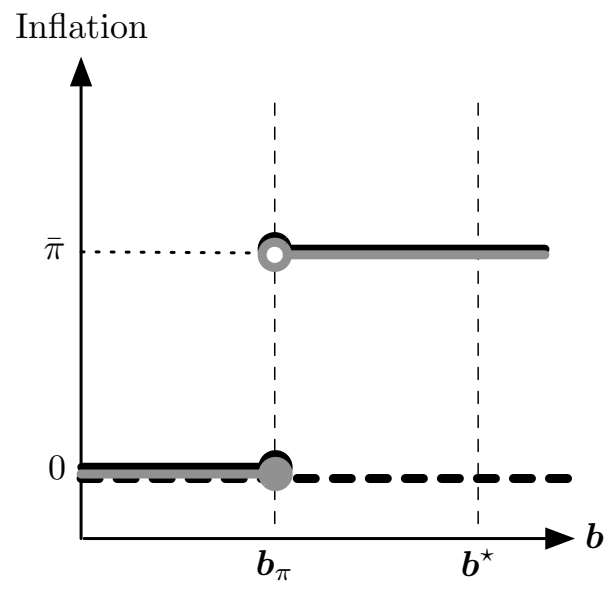

(c) Inflation Policy
Consumption

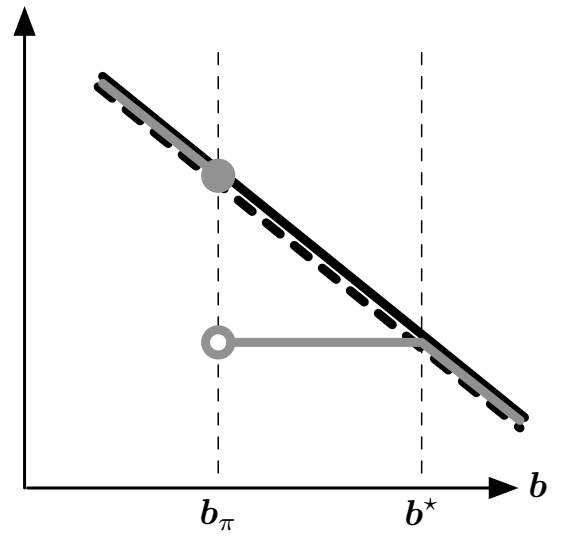

(b) Consumption Policy

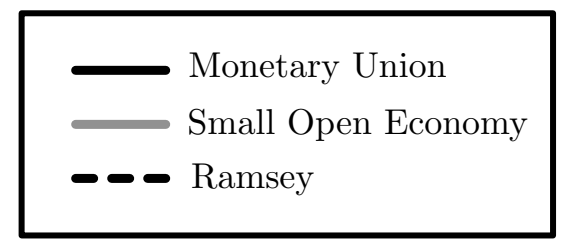

Figure 2: Fiscal Externality, Value of Commitment, Value of Coordination

This figure depicts three environments for fiscal and monetary policy. The solid black line depicts our equilibrium Monetary Union value and policy functions. The solid shaded line depicts the value and associated policies for a unified monetary-fiscal authority (Small Open Economy). The dashed line depicts the Ramsey allocation, in which monetary policy is chosen at date zero and implemented with commitment. Note that in panel (b) the consumption policies in the Monetary Union and the Ramsey allocation are identical. Conversely, in panel (c), the inflation policies of the Monetary Union and the SOE are identical. In panel (a), we see that the SOE value is intermediate between the Ramsey and the Monetary Union. 


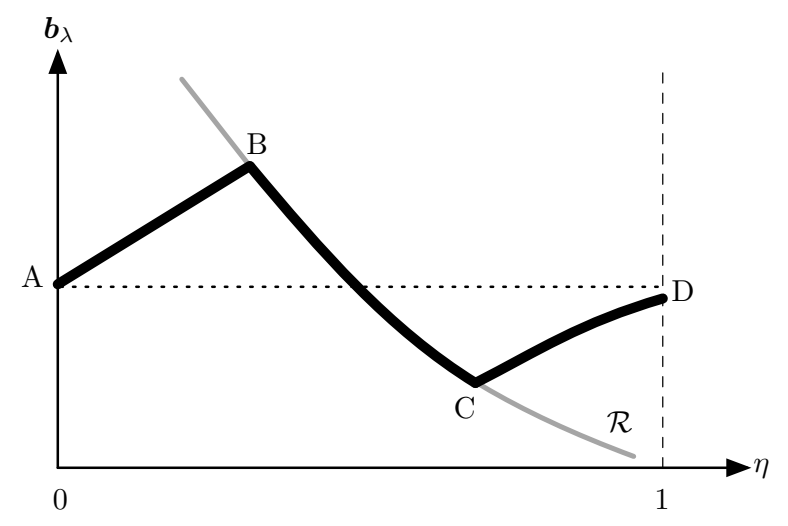

Figure 3: Crisis threshold and debt composition

This figure depicts the equilibrium crisis threshold $\boldsymbol{b}_{\lambda}$ as a function of the parameter $\eta$, which defines the fraction of debtors in the monetary union. The bold line is the equilibrium threshold at each $\eta$. The shaded line labelled $\mathcal{R}$ is defined in the text. 


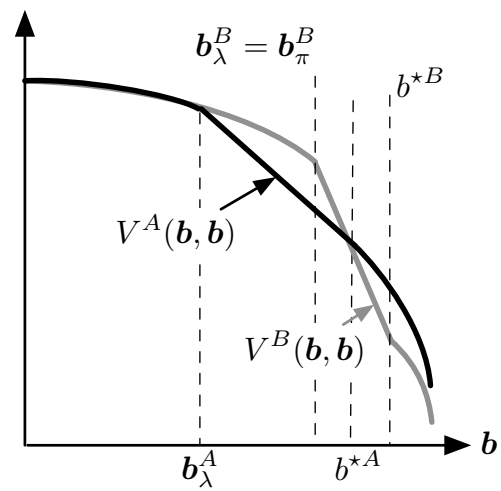

(a) Value

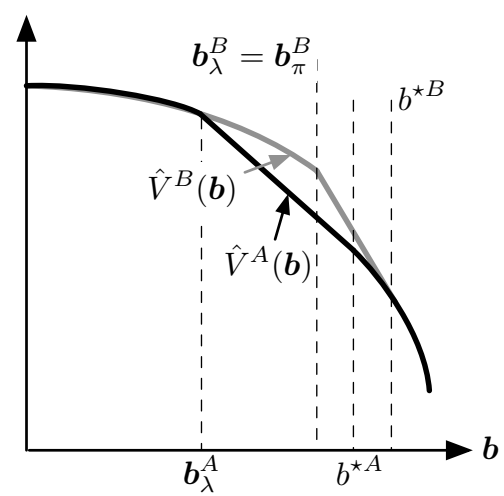

(b) Value Net of Inflation

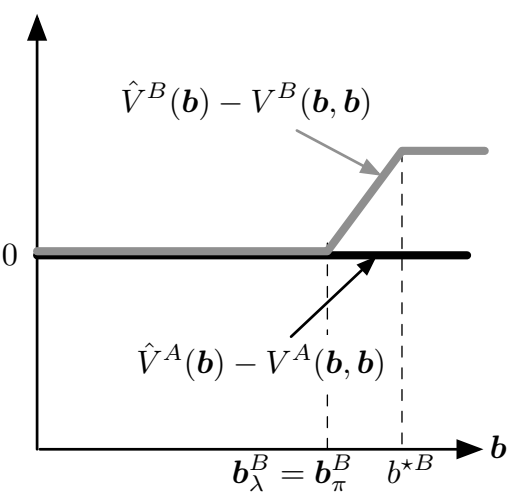

(c) Inflation Costs

Figure 4: Welfare and debt composition

This figure depicts the value function (panel a), the value net of inflation (panel b), and the inflation costs (panel c) for two values of $\eta$. The value in panel (a) is the value in panel (b) minus the costs in panel (c). The black line corresponds to $\eta=0$, which is the zero-inflation case. The shaded line depicts the case of $\eta>0$ from point $B$ in Figure 3 . 